\title{
An ES-MITC3 Finite Element Method Based on Higher-Order Shear Deformation Theory for Static and Free Vibration Analyses of FG Porous Plates Reinforced by GPLs
}

\author{
The-Van Tran, ${ }^{1}$ Tuan-Duy Tran, ${ }^{2}$ Quoc Hoa Pham $\mathbb{D}^{3,4}$ Trung Nguyen-Thoi, ${ }^{3,4}$ \\ and Van Ke Tran ${ }^{5}$ \\ ${ }^{1}$ Faculty of Mechanical Engineering, Tran Dai Nghia University, Ho Chi Minh City, Vietnam \\ ${ }^{2}$ Faculty of Mechanical Engineering, Ho Chi Minh City University of Technology, \\ Vietnam National University Ho Chi Minh City, Ho Chi Minh City, Vietnam \\ ${ }^{3}$ Division of Computational Mathematics and Engineering, Institute for Computational Science, Ton Duc Thang University, \\ Ho Chi Minh City, Vietnam \\ ${ }^{4}$ Faculty of Civil Engineering, Ton Duc Thang University, Ho Chi Minh City, Vietnam \\ ${ }^{5}$ Faculty of Mechanical Engineering, Le Qui Don University, Hanoi, Vietnam
}

Correspondence should be addressed to Quoc Hoa Pham; phamquochoa@tdtu.edu.vn

Received 22 April 2020; Accepted 2 June 2020; Published 30 June 2020

Academic Editor: Nerio Tullini

Copyright (C) 2020 The-Van Tran et al. This is an open access article distributed under the Creative Commons Attribution License, which permits unrestricted use, distribution, and reproduction in any medium, provided the original work is properly cited.

\begin{abstract}
An edge-based smoothed finite element method (ES-FEM) combined with the mixed interpolation of tensorial components technique (MITC) for triangular elements, named as ES-MITC3, was recently proposed to enhance the accuracy of the original MITC3 for analysis of plates and shells. In this study, the ES-MITC3 is extended to the static and vibration analysis of functionally graded (FG) porous plates reinforced by graphene platelets (GPLs). In the ES-MITC3, the stiffness matrices are obtained by using the strain smoothing technique over the smoothing domains created by two adjacent triangular elements sharing an edge. The effective material properties are variable through the thickness of plates including Young's modulus estimated via the Halpin-Tsai model and Poisson's ratio and the mass density according to the rule of mixture. Three types of porosity distributions and GPL dispersion pattern into the metal matrix are examined. Numerical examples are given to demonstrate the performance of the present approach in comparison with other existing methods. Furthermore, the effect of several parameters such as GPL weight fraction, porosity coefficient, porosity distribution, and GPL dispersion patterns on the static and free vibration responses of FG porous plates is discussed in detail.
\end{abstract}

\section{Introduction}

In recent years, FG porous material has attracted a great interest from many researchers over the world due to their superior mechanical properties such as lightweight, wear resistance, and high strength. These properties make FG porous structures to be very suitable to apply for civil engineering, aerospace structures, nuclear plants, and other applications. In this regard, Rezaei et al. [1] presented the analytical approach based on Reddy's third-order shear deformation theory to analyse the free vibration of thick porous plates. Leclaire et al. [2] used the classical theory and the stress-strain relations of Biot to investigate the free vibration of the thin porous plates saturated by a fluid. Zhao et al. [3] introduced a semianalytical method based on a modified Fourier series to study the vibration of FG porous shells. Coskun et al. [4] developed the analytical solutions using the general third-order shear deformation theory (TSDT) for the static, free vibration, and buckling analyses of FG porous microplates. Nguyen et al. [5] studied the dynamic response of FG porous plates resting on elastic foundation under thermal and mechanical loads by the 
analytical method and the first-order shear deformation theory (FSDT). Phung et al. [6] combined between the thirdorder shear deformation theory and the isogeometric analysis to study nonlinear transient of the FG porous plates in hygro-thermo-mechanical environment. Barati used the analytical approach based on nonlocal strain gradient theory to investigate the free vibration of FG porous nanoshells [7] and the forced vibration of FG porous nanoplates [8]. Shahverdi and Barati [9] introduced a general nonlocal strain gradient (NSG) elasticity model to analyse the vibration of FG porous nanoplates resting on an elastic substrate. Forsat et al. [10] studied the transient response of FG porous nanoshell subjected to different impulsive loadings using the nonlocal strain gradient theory. Mirjavadi et al. [11] examined the dynamic response of FG porous cylindrical microshells under the moving loads using strain gradient size dependency. Fenjan et al. [12] used the differential quadrature method combined with the nonlocal strain gradient theory to analyse the mechanical-hygrothermal vibrations of the FG porous plates resting on the viscoelastic foundation. Ebrahimi et al. [13] provided an analytical approach for the free vibration of smart FG porous plates with different boundary conditions. Barati and Zenkour [14] explored the free vibration of FG porous nanoplates using the higher-order shear deformation theory, and they also used a refined four-variable plate theory to study the vibration behavior of FG porous plates with piezoelectric [15]. Also, Barati and Shahverdi [16] proposed the higher-order refined four-variable plate theory to examine the nonlinear vibration of the FG porous nanoplates.

Although there are many advantages as mentioned above, the FG porous materials are still limited in several engineering applications due to the existence of internal pores which cause the significant decrease of stiffness of structures. To deal with this problem (i.e., increase the stiffness of structure but still retain their lightweight properties), carbon nanotubes (CNTs) [17] or graphene platelets (GPLs) [18-21] have been used to reinforce the FG porous structures. However, in [22], Li and co-workers demonstrated that the reinforcement of GPLs is better than that of CNTs because GPLs have low manufacturing cost and help increase the load carrying capability by improving the bonding with the matrix. Many research studies have been conducted to investigate the effect of GPLs on behaviors of FG porous structures by using many various approaches. Seyed et al. [23] presented a semianalytical approach based on the FSDT to solve dynamic behavior of FG porous shells reinforced by GPLs subjected to radial dynamic load. Barati et al. [24] examined the free vibration response of FG porous shells using the analytical method and the FSDT. Their work showed that the porosity distribution and GPL distribution significantly affect the vibration frequencies of FG porous shells. Using the analytical approach via the FSDT and Chebyshev-Ritz method, Yang et al. [25] reported the buckling and free vibration behavior of FG porous plates reinforced by GPLs. Gao et al. [26] used the differential quadrature method to investigate the free vibration of FG porous plates reinforced with GPLs resting on the elastic foundation using different boundary conditions. Hamilton's principle and the classic plate theory with von Karman strains assumption are applied to derive the equations of emotion of plates in their paper. Recently, the isogeometric analysis (IGA) method [27-30] is also applied for analysis of FG porous structures by many researchers. Based on the FSDT and TSDT, Li et al. [31] introduced the static, free vibration, and buckling behaviors of FG porous plates reinforced by GPLs. Also, Nguyen et al. [32] developed the IGA approach based on Bézier extraction to examine the static bending and transient response of piezoelectric FG porous plates reinforced by GPLs. In [33], Wang and coworkers proposed an analytical solution and Navier technique using the higher-order shear deformation theory (HSDT) to study the FG porous doubly curved shell reinforced by GPLs. In addition, Nguyen et al. [34] proposed the polygonal finite element method to investigate the static bending, free vibration, and dynamic behavior of FG porous and piezoelectric FG porous plates with GPL reinforcement. In this study, they used the Halpin-Tsai model to establish the relationship between the porosity coefficient and Young's modulus.

In an effort to improve the convergence and accuracy for analysis of the plate and shell structures, the original MITC3 element [35] has been combined with the ES-FEM [36-41] to give the so-called ES-MITC3 element [42-46]. The numerical results in these works showed that the ES-MITC3 has the following superior properties [42]: (1) the ES-MITC3 uses only three-node triangular elements which are easy in mesh generation even for complicated geometry domains; (2) the ES-MITC3 can eliminate transverse shear locking even with the ratio of the thickness to the length of the structures reaching $\mathbf{1 0}^{-8}$ while many other elements are limited with $10^{-5}$; (3) the accuracy of the ES-MITC3 is less affected by the badly shaped elements or mesh distortions; (4) the ES-MITC3 has better accuracy than the existing triangular elements such as MITC3 [35], DSG3 [47], and CSDSG3 [48] and is a good competitor against the quadrilateral element MITC4 [49].

This article further extends the ES-MITC3 to investigate for static bending and vibration responses of FG porous plates reinforced by GPLs. The HSDT is utilized in approximation formulation of displacement field to avoid using the transverse shear correction factors and to enhance the accuracy of the shear stresses across the thickness of the FG porous plates. The different porosity distribution types and the GPL patterns including symmetry, asymmetry, and uniformity across the plate thickness are considered in the present work. The obtained results are compared with other published approaches in the literature to demonstrate the accuracy and reliability of the proposed method. Moreover, the influences of material parameters such as GPL weight fraction, the porosity coefficient, the geometrical sizes of GPLs, and the distribution patterns on the static and free vibration of FG porous plates are investigated in detail. 


\section{Material Models of GPL-Reinforced FG Porous Plates}

2.1. The Distribution of Porosity. There are three types of porosity distribution along the thickness of FG porous plates including symmetrical (P-S), asymmetrical (P-A), and uniform (P-U), as shown in Figure 1. Young's modulus $E(z)$, shear modulus $G(z)$, and mass density $\rho(z)$ of FG porous plates with three porosity distribution types can be given as follows [34]:

$$
\left\{\begin{array}{l}
E(z)=E_{1}\left[1-e_{0} \lambda(z)\right], \\
G(z)=G_{1}\left[1-e_{0} \lambda(z)\right], \\
\rho(z)=\rho_{1}\left[1-e_{m} \lambda(z)\right],
\end{array}\right.
$$

where

$$
\lambda(z)=\left\{\begin{array}{l}
\cos \left(\frac{\pi z}{h}\right), \text { symmetry porosity distribution }(\mathrm{S}-\mathrm{P}), \\
\cos \left(\frac{\pi z}{2 h}+\frac{\pi}{4}\right), \text { asymmetry porosity distribution }(\mathrm{A}-\mathrm{P}), \\
\lambda, \text { uniform porosity distribution }(\mathrm{U}-\mathrm{P}),
\end{array}\right.
$$

in which $E_{1}, G_{1}$, and $\rho_{1}$ denote the maximum values of Young's modulus, shear modulus, and mass density of the FG plates without internal pores, respectively. The coefficient of porosity $e_{0}$ can be determined by

$$
e_{0}=1-\frac{E_{2}^{\prime}}{E_{1}^{\prime}}
$$

where $E_{1}^{\prime}$ and $E_{2}^{\prime}$ are the maximum and minimum values of Young's modulus for two nonuniform porosity distribution types (S-P and A-P). Furthermore, $E^{\prime}$ represents Young's modulus for U-P case as shown in Figure 2.

The mechanical property of closed-cell cellular solids according to Gaussian random field can be defined as [50]

$$
\begin{gathered}
\frac{E(z)}{E_{1}}\left(\frac{\left(\rho(z) / \rho_{1}\right)+0.121}{1.121}\right)^{2.3}, \\
\left(0.15<\frac{\rho(z)}{\rho_{1}}<1\right) .
\end{gathered}
$$

From equation (4), the coefficient of mass density can be derived as follows:

$$
e_{m}=\frac{1.121\left(1-\sqrt[2.3]{1-e_{0} \lambda(z)}\right)}{\lambda(z)}
$$

Using the closed-cell Gaussian random field scheme, Poisson's $v(z)$ can be obtained as [51]

$$
v(z)=0.22 p^{\prime}+v_{1}\left(0.342 p^{2}-1.21 p^{1}+1\right),
$$

where $v_{1}$ denotes Poisson's ratio of the pure matrix material without pores and

$$
p^{\prime}=1-\frac{\rho(z)}{\rho_{1}}=1.121\left(1-\sqrt[2.3]{1-e_{0} \lambda(z)}\right) .
$$

It is noted that the total mass $M$ of the FG porous plates with different porosity distributions does not change and can be calculated by

$$
M=\int_{-h / 2}^{h / 2} \rho(z) \mathrm{d} z .
$$

In equation (2), the coefficient of porosity $\lambda$ for U-P case can be written as [26]

$$
\lambda=\frac{1}{e_{0}}-\frac{1}{e_{0}}\left(\frac{\left(M / \rho_{1} h\right)+0.121}{1.121}\right)^{2.3} .
$$

2.2. The GPL Distribution. In this paper, three dispersion patterns such as symmetry distribution (S-GPL), asymmetry distribution (A-GPL), and uniform distribution (U-GPL), as depicted in Figure 2, are considered. The volume fraction of GPLs varies smoothly through the place's thickness direction which can be given as [25]

$$
V_{G P L}=\left\{\begin{array}{l}
S_{i 1}[1-\cos (\pi z / h)], \text { symmetry distribution }(\mathrm{S}-\mathrm{GPL}), \\
S_{i 2}\left[1-\cos \left(\frac{\pi z}{2 h}+\pi / 4\right)\right], \text { asymmetry distribution }(\mathrm{A}-\mathrm{GPL}), \\
S_{i 3}, \text { uniform distribution }(\mathrm{U}-\mathrm{GPL}),
\end{array}\right.
$$

where $S_{i j}$ with $j=1,2,3$ is the maximum value of GPL volume fraction and $i=1,2,3$ corresponding to the S-P, A-P, and U-P cases, respectively.

$$
\begin{gathered}
S_{i j} \int_{-h / 2}^{h / 2}\left[\begin{array}{c}
{[1-\cos (\pi z / h)]} \\
{\left[1-\cos \left(\frac{\pi z}{2 h}+\pi / 4\right)\right]} \\
1
\end{array}\right]\left[1-e_{m} \lambda(z)\right] \mathrm{d} z \\
=\frac{\Lambda_{G P L \rho m}}{\Lambda_{G P L \rho m}+\rho_{G P L}-\Lambda_{G P L \rho G P L}} \int_{-h / 2}^{h / 2}\left[1-e_{m} \lambda(z)\right] \mathrm{d} z .
\end{gathered}
$$

To calculate $S_{i j}$, equation (12) can be rewritten as follows: 


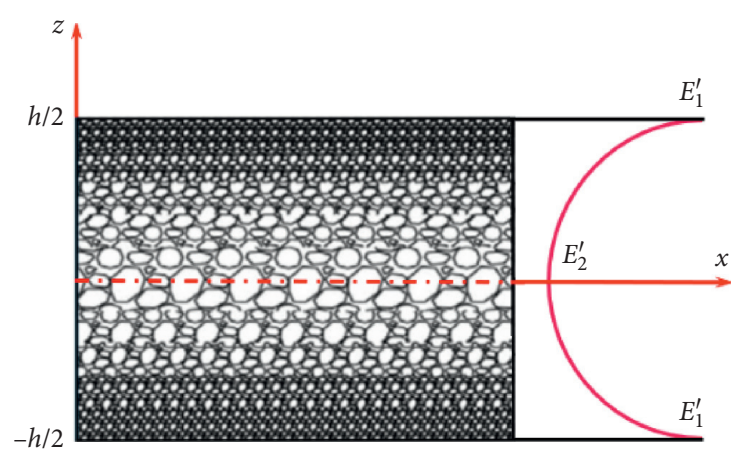

(a)

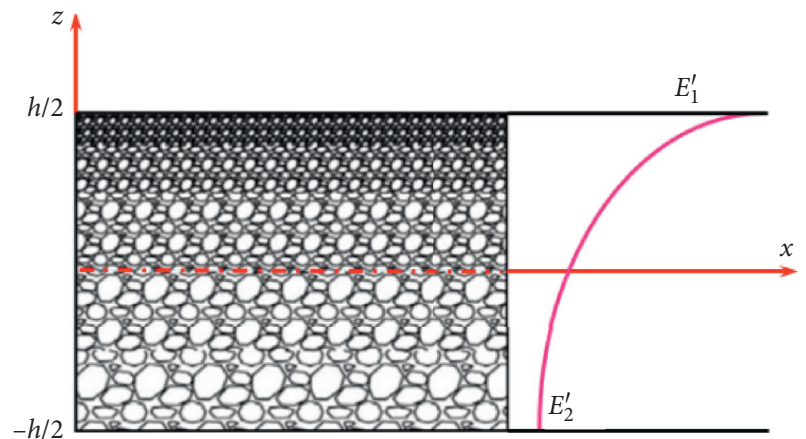

(b)

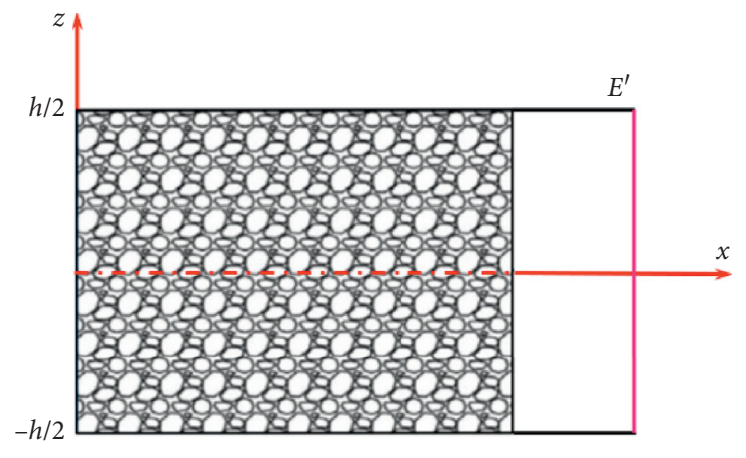

(c)

FIgURE 1: The porosity distribution types.

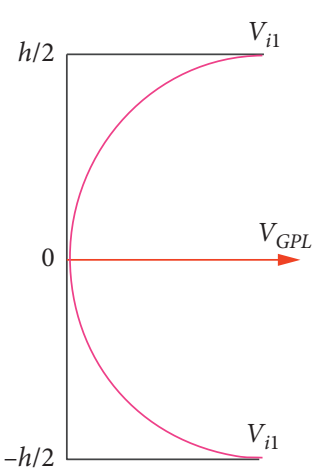

(a)

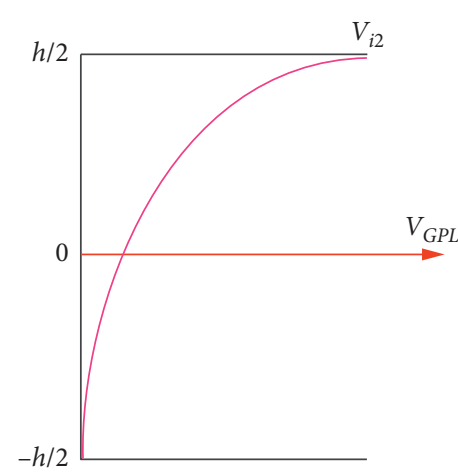

(b)

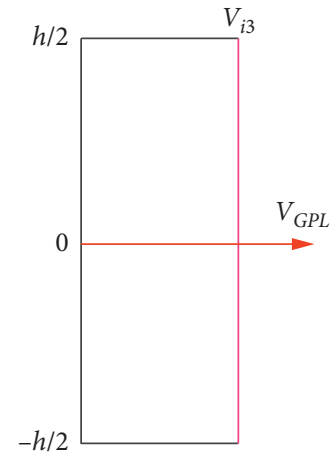

(c)

FIGURE 2: The GPL dispersion patterns.

$$
\left\{\begin{array}{l}
S_{i 1} \sum_{j=1}^{n_{l}}\left\{[1-\cos (\pi z / h)] \frac{\rho\left(z_{j}\right)}{\rho_{1}}\right\}, \\
S_{i 2} \sum_{j=1}^{n_{l}}\left\{\left[1-\cos \left(\frac{\pi z}{2 h}+\pi / 4\right)\right] \frac{\rho\left(z_{j}\right)}{\rho_{1}}\right\} \\
=\frac{\Lambda_{G P L \rho m}}{\Lambda_{G P L \rho m}+\rho_{G P L}-\Lambda_{G P L \rho G P L}} \sum_{j=1}^{n_{l}} \frac{\rho\left(z_{j}\right)}{\rho_{1}} \\
S_{i 3} \frac{\rho\left(z_{j}\right)}{\rho_{1}}
\end{array}\right.
$$

in which

$$
z_{j}=\left(\frac{1}{2}+\frac{1}{2 n_{l}}-\frac{j}{n_{l}}\right)
$$

Effective Young's modulus of the FG reinforced by GPLs without internal pores is determined by the Halpin-Tsai micromechanics model as [52]

$$
E_{1}=\frac{3}{8}\left(\frac{1+\xi_{L} \eta_{L} V_{G P L}}{1-\eta_{L} V_{G P L}}\right) E_{m}+\frac{5}{8}\left(\frac{1+\xi_{W} \eta_{W} V_{G P L}}{1-\eta_{W} V_{G P L}}\right) E_{m}
$$

where 


$$
\begin{aligned}
\xi_{L} & =\frac{2 L_{G P L}}{t_{G P L}}, \\
\xi_{W} & =\frac{2 W_{G P L}}{t_{G P L}} \\
\eta_{L} & =\frac{\left(E_{G P L} / E_{m}\right)-1}{\left(E_{G P L} / E_{m}\right)+\xi_{L}}, \\
\eta_{W} & =\frac{\left(E_{G P L} / E_{m}\right)-1}{\left(E_{G P L} / E_{m}\right)+\xi_{W}},
\end{aligned}
$$

in which $W_{G P L}, L_{G P L}$, and $t_{G P L}$ are average width, length, and thickness of GPLs, respectively, and $E_{G P L}$ and $E_{m}$ are Young's moduli of GPLs and metal matrix, respectively.

The mass density $\rho_{1}$ and Poisson's ratio $v_{1}$ of the GPL reinforced metal can be calculated as

$$
\begin{aligned}
& \rho_{1}=\rho_{G P L} V_{G P L}+\rho_{M} V_{M}, \\
& v_{1}=v_{G P L} V_{G P L}+v_{M} V_{M},
\end{aligned}
$$

where $\rho_{G P L}, v_{G P L}$, and $V_{G P L}$ are the mass density, Poisson's ratio, and volume fraction of GPLs, respectively, and $\rho_{M}, v_{M}$, and $V_{M}$ are the mass density, Poisson's ratio, and volume fraction of the metal, respectively.

\section{The Higher-Order Shear Deformation Theory and Weak Form for FG Porous Plates}

3.1. $C^{0}$-Type Higher-Order Shear Deformation Theory for FG Porous Plates. The displacement of FG porous plates in present work based on the $\mathrm{C}^{0}$-HSDT [53] model can be expressed as

$$
\left\{\begin{array}{l}
u(x, y, z)=u_{0}(x, y)+\left(z+c z^{3}\right) \theta_{x}(x, y)+c z^{3} \phi_{x}(x, y), \\
v(x, y, z)=v_{0}(x, y)+\left(z+c z^{3}\right) \theta_{y}(x, y)+c z^{3} \phi_{y}(x, y), \\
w(x, y, z)=w_{0}(x, y),
\end{array}\right.
$$

in which $u$ and $v, w$ are middle-surface displacements and $\theta_{x}$ and $\theta_{y}$ are the independent rotations of the normal in $x z$ and $y z$ planes, respectively; $\phi_{x}$ and $\phi_{y}$ are warping functions which replace derivative of deflection according to Reddy's HSDT; and $c=-4 / 3 h^{2}$.

For a bending plate, the strain field can be expressed as follows:

$$
\boldsymbol{\varepsilon}=\boldsymbol{\varepsilon}_{m}+\mathbf{Z} \boldsymbol{\kappa}^{(1)}+z^{3} \boldsymbol{\kappa}^{(2)},
$$

where

The membrane strain is given as

$$
\boldsymbol{\varepsilon}_{m}=\left\{\begin{array}{c}
u_{0, x} \\
v_{0, y} \\
u_{0, y}+v_{0, x}
\end{array}\right\}
$$

The bending strains are written as

$$
\begin{aligned}
& \mathbf{\kappa}^{(1)}=\left\{\begin{array}{c}
\theta_{x, x} \\
\theta_{y, y} \\
\theta_{x, y}+\theta_{y, x}
\end{array}\right\}, \\
& \mathbf{\kappa}^{(2)}=c\left\{\begin{array}{c}
\theta_{x, x}+\phi_{x, x} \\
\theta_{y, y}+\phi_{y, y} \\
\theta_{x, y}+\theta_{y, x}+\phi_{x, y}+\phi_{y, x}
\end{array}\right\},
\end{aligned}
$$

and the transverse shear strain is defined as

$$
\boldsymbol{\gamma}=\boldsymbol{\gamma}^{(0)}+z^{2} \boldsymbol{\gamma}^{(1)}
$$

with

$$
\begin{aligned}
& \boldsymbol{\gamma}^{(0)}=\left\{\begin{array}{l}
w_{0, x}+\theta_{x} \\
w_{0, y}+\theta_{y}
\end{array}\right\} ; \\
& \boldsymbol{\gamma}^{(1)}=c\left\{\begin{array}{l}
\phi_{x}+\theta_{x} \\
\phi_{y}+\theta_{y}
\end{array}\right\} .
\end{aligned}
$$

From Hooke's law, the linear stress-strain relations of FG porous plates can be expressed as

$$
\left\{\begin{array}{c}
\sigma_{x} \\
\sigma_{y} \\
\tau_{x y} \\
\tau_{x z} \\
\tau_{y z}
\end{array}\right\}=\left[\begin{array}{ccccc}
Q_{11} & Q_{12} & 0 & 0 & 0 \\
Q_{21} & Q_{22} & 0 & 0 & 0 \\
0 & 0 & Q_{66} & 0 & 0 \\
0 & 0 & 0 & Q_{55} & 0 \\
0 & 0 & 0 & 0 & Q_{44}
\end{array}\right]\left\{\begin{array}{c}
\varepsilon_{x} \\
\varepsilon_{y} \\
\gamma_{x y} \\
\gamma_{x z} \\
\gamma_{y z}
\end{array}\right\},
$$

where

$$
\begin{aligned}
& Q_{11}=\frac{E_{11}}{1-v_{12} v_{21}}, \\
& Q_{22}=\frac{E_{22}}{1-v_{12} v_{21}}, \\
& Q_{12}=Q_{21} \frac{v_{21} E_{11}}{1-v_{12} v_{21}}, \\
& Q_{44}=G_{23}, \\
& Q_{55}=G_{13}, \\
& Q_{66}=G_{12},
\end{aligned}
$$

in which $E_{11}$ and $E_{22}$ are effective Young's moduli; $G_{12}, G_{13}$, and $G_{23}$ denote the effective shear moduli; and $v_{12}$ and $v_{21}$ represent Poisson's ratios.

3.2. Weak Form Equations. To obtain the governing equations of FG porous plates reinforced by GPLs, Hamilton's principle is applied in the following form:

$$
\int_{t_{1}}^{t_{2}}(\delta \mathscr{U}+\delta \mathscr{V}-\delta \mathscr{K}) \mathrm{d} t=0,
$$


where $\mathscr{U}, \mathscr{V}$, and $\mathscr{K}$ are the strain energy, the work done by external loads, and the kinetic energy of FG porous plates, respectively.

The strain energy is expressed as

$$
\mathcal{U}=\frac{1}{2} \int_{\Omega}\left(\boldsymbol{\varepsilon}^{T} \mathbf{D} \boldsymbol{\varepsilon}+\boldsymbol{\gamma}^{T} \mathbf{C} \boldsymbol{\gamma}\right) \mathrm{d} \Omega,
$$

in which $\boldsymbol{\varepsilon}^{T}=\left[\boldsymbol{\varepsilon}_{m} \boldsymbol{\kappa}^{(1)} \boldsymbol{\kappa}^{(2)}\right]$ and $\boldsymbol{\gamma}^{T}=\left[\boldsymbol{\gamma}^{(0)} \boldsymbol{\gamma}^{(1)}\right]$.

$$
\begin{aligned}
& \mathbf{D}=\left[\begin{array}{lll}
\mathbf{A} & \mathbf{B} & \mathbf{E} \\
\mathbf{E} & \mathbf{D} & \mathbf{F} \\
\mathbf{E} & \mathbf{F} & \mathbf{H}
\end{array}\right], \\
& \mathbf{C}=\left[\begin{array}{ll}
\mathbf{A}_{s} & \mathbf{B}_{s} \\
\mathbf{B}_{s} & \mathbf{D}_{s}
\end{array}\right],
\end{aligned}
$$

where A, B, D, E, F, H, $\mathbf{A}_{s}, \mathbf{B}_{s}, \mathbf{D}_{s}$ can be given by

$$
\begin{aligned}
(\mathbf{A}, \mathbf{B}, \mathbf{D}, \mathbf{E}, \mathbf{F}, \mathbf{H})= & \int_{-h / 2}^{h / 2}\left(1, z, z^{2}, z^{3}, z^{4}, z^{6}\right) \\
& \cdot\left[\begin{array}{ccc}
Q_{11} & Q_{12} & 0 \\
Q_{21} & Q_{22} & 0 \\
0 & 0 & Q_{66}
\end{array}\right] \mathrm{d} z, \\
(\text { As, Bs, Ds })= & \int_{-h / 2}^{h / 2}\left(1, z^{2}, z^{4}\right)\left[\begin{array}{cc}
Q_{55} & 0 \\
0 & Q_{44}
\end{array}\right] \mathrm{d} z .
\end{aligned}
$$
by

The work done by external transverse loads is expressed

$$
\mathscr{V}=\int_{\Omega} q w \mathrm{~d} \Omega .
$$

The kinetic energy is given by

$$
\mathscr{K}=\frac{1}{2} \int_{\Omega} \dot{\operatorname{umud}} \Omega,
$$

where $\mathbf{u}^{T}=\left[u_{0} v_{0} w_{0} \theta_{x} \theta_{y} \phi_{x} \phi_{y}\right]$ and $\mathbf{m}$ is the mass matrix which is defined by

$$
\mathbf{m}=\left[\begin{array}{ccccccc}
I_{1} & 0 & 0 & I_{2} & 0 & c / 3 I_{4} & 0 \\
& I_{1} & 0 & 0 & I_{2} & 0 & c / 3 I_{4} \\
& & I_{1} & 0 & 0 & 0 & 0 \\
& & & I_{3} & 0 & c / 3 I_{5} & 0 \\
& & & & I_{3} & 0 & c / 3 I_{5} \\
& & & & & c^{2} / 9 I_{7} & 0 \\
\text { sym } & & & & & & c^{2} / 9 I_{7}
\end{array}\right],
$$

with $\left(I_{1}, I_{2}, I_{3}, I_{4}, I_{5}, I_{7}\right)=\int_{-t / 2}^{t / 2} \rho(z)\left(1, z, z^{2}, z^{3}, z^{4}, z^{6}\right) \mathrm{d} z$.

Substituting equations (29), (33), and (34) into equation (28), weak formulation for static and free vibration of FG porous plates, respectively, is finally obtained as

$$
\begin{aligned}
& \int_{\Omega} \delta \boldsymbol{\varepsilon}^{T} \mathbf{D} \boldsymbol{\varepsilon} \mathrm{d} \Omega+\int_{\Omega} \delta \boldsymbol{\gamma}^{T} \mathbf{C} \boldsymbol{\gamma} \Omega=\int_{\Omega} q \delta w \mathrm{~d} \Omega \\
& \int_{\Omega} \delta \boldsymbol{\varepsilon}^{T} \mathbf{D} \boldsymbol{\varepsilon} \mathrm{d} \Omega+\int_{\Omega} \delta \boldsymbol{\gamma}^{T} \mathbf{C} \boldsymbol{\gamma} \Omega=\int_{\Omega} \operatorname{umud} \Omega .
\end{aligned}
$$

\section{Formulation of an ES-MITC3 Method for FG Porous Plates}

4.1. Formulation of Finite Element Based on the MITC3. The bounded domain $\Omega$ is discretized into $n^{e}$ finite threenode triangular elements with $n^{n}$ nodes such that $\Omega \approx \sum_{e=1}^{n^{e}} \Omega_{e}$ and $\Omega_{e} \cap \Omega_{j}=\phi, i \neq j$. Then, the generalized displacements at any point $\mathbf{u}^{e}=\left[u_{j}^{e}, v_{j}^{e}, w_{j}^{e}, \theta_{x j}^{e}, \theta_{y j}^{e}\right.$, $\left.\phi_{x j}^{e}, \phi_{y j}^{e}\right]^{T}$ for elements of the FG porous plates can be approximated as

$$
\begin{aligned}
\mathbf{u}^{e} & =\sum_{j=1}^{n^{n e}}\left[\begin{array}{ccccccc}
N_{I}(\mathrm{x}) & 0 & 0 & 0 & 0 & 0 & 0 \\
0 & N_{I}(\mathrm{x}) & 0 & 0 & 0 & 0 & 0 \\
0 & 0 & N_{I}(\mathrm{x}) & 0 & 0 & 0 & 0 \\
0 & 0 & 0 & N_{I}(\mathrm{x}) & 0 & 0 & 0 \\
0 & 0 & 0 & 0 & N_{I}(\mathrm{x}) & 0 & 0 \\
0 & 0 & 0 & 0 & 0 & N_{I}(\mathrm{x}) & 0 \\
0 & 0 & 0 & 0 & 0 & 0 & N_{I}(\mathrm{x})
\end{array}\right] \mathbf{d}_{j}^{e} \\
& =\sum_{j=1}^{n^{n e}} \mathbf{N}(\mathrm{x}) \mathbf{d}_{j}^{e},
\end{aligned}
$$

where $n^{\text {ne }}$ is the number of nodes of the plate element and $N(\mathrm{x})$ and $\mathbf{d}_{j}^{e}=\left[u_{j}^{e}, v_{j}^{e}, w_{j}^{e}, \theta_{x j}^{e}, \theta_{y j}^{e}, \phi_{x j}^{e}, \phi_{y j}^{e}\right]^{T}$ are the shape function and the nodal degrees of freedom (dof) of $\mathbf{u}^{e}$ associated with the $j$ th node of the element, respectively.

The linear membrane and the bending strains of a triangular element can be expressed in matrix forms as follows:

$$
\begin{aligned}
\boldsymbol{\varepsilon}_{m}^{e} & =\left[\begin{array}{lll}
\mathbf{B}_{m 1}^{e} & \mathbf{B}_{m 2}^{e} & \mathbf{B}_{m 3}^{e}
\end{array}\right] \mathbf{d}^{e}=\mathbf{B}_{m}^{e} \mathbf{d}^{e}, \\
\boldsymbol{\kappa}^{e(1)} & =\left[\begin{array}{lll}
\mathbf{B}_{b 1}^{e(1)} & \mathbf{B}_{b 2}^{e(1)} & \mathbf{B}_{b 3}^{e(1)}
\end{array}\right] \mathbf{d}^{e}=\mathbf{B}_{b}^{e(1)} \mathbf{d}^{e}, \\
\boldsymbol{\kappa}^{e(2)} & =\left[\begin{array}{lll}
\mathbf{B}_{b 1}^{e(2)} & \mathbf{B}_{b 2}^{e(2)} & \mathbf{B}_{b 3}^{e(2)}
\end{array}\right] \mathbf{d}^{e}=\mathbf{B}_{b}^{e(2)} \mathbf{d}^{e},
\end{aligned}
$$

where

$$
\begin{aligned}
\mathbf{B}_{m 1}^{e} & =\frac{1}{2 A_{e}}\left[\begin{array}{ccccccc}
b-c & 0 & 0 & 0 & 0 & 0 & 0 \\
0 & d-a & 0 & 0 & 0 & 0 & 0 \\
d-a & b-c & 0 & 0 & 0 & 0 & 0
\end{array}\right], \\
\mathbf{B}_{m 2}^{e} & =\frac{1}{2 A_{e}}\left[\begin{array}{ccccccc}
c & 0 & 0 & 0 & 0 & 0 & 0 \\
0 & -d & 0 & 0 & 0 & 0 & 0 \\
-d & c & 0 & 0 & 0 & 0 & 0
\end{array}\right], \\
\mathbf{B}_{m 3}^{e} & =\frac{1}{2 A_{e}}\left[\begin{array}{ccccccc}
-b & 0 & 0 & 0 & 0 & 0 & 0 \\
0 & a & 0 & 0 & 0 & 0 & 0 \\
a & -b & 0 & 0 & 0 & 0 & 0
\end{array}\right], \\
\mathbf{B}_{b 1}^{e(1)} & =\frac{1}{2 A_{e}}\left[\begin{array}{lllllll}
0 & 0 & 0 & b-c & 0 & 0 & 0 \\
0 & 0 & 0 & 0 & d-a & 0 & 0 \\
0 & 0 & 0 & d-a & b-c & 0 & 0
\end{array}\right],
\end{aligned}
$$




$$
\begin{aligned}
& \mathbf{B}_{b 2}^{e(1)}=\frac{1}{2 A_{e}}\left[\begin{array}{ccccccc}
0 & 0 & 0 & c & 0 & 0 & 0 \\
0 & 0 & 0 & 0 & -d & 0 & 0 \\
0 & 0 & 0 & -d & c & 0 & 0
\end{array}\right], \\
& \mathbf{B}_{b 3}^{e(1)}=\frac{1}{2 A_{e}}\left[\begin{array}{ccccccc}
0 & 0 & 0 & -b & 0 & 0 & 0 \\
0 & 0 & 0 & 0 & a & 0 & 0 \\
0 & 0 & 0 & a & -b & 0 & 0
\end{array}\right], \\
& \mathbf{B}_{b 1}^{e(2)}=\frac{1}{2 A_{e}} \frac{c}{3}\left[\begin{array}{ccccccc}
0 & 0 & 0 & b-c & 0 & b-c & 0 \\
0 & 0 & 0 & 0 & d-a & 0 & d-a \\
0 & 0 & 0 & d-a & b-c & d-a & b-c
\end{array}\right], \\
& \mathbf{B}_{b 2}^{e(2)}=\frac{1}{2 A_{e}} \frac{c}{3}\left[\begin{array}{ccccccc}
0 & 0 & 0 & c & 0 & c & 0 \\
0 & 0 & 0 & 0 & -d & 0 & -d \\
0 & 0 & 0 & -d & c & -d & c
\end{array}\right], \\
& \mathbf{B}_{b 3}^{e(2)}=\frac{1}{2 A_{e}} \frac{c}{3}\left[\begin{array}{ccccccc}
0 & 0 & 0 & -b & 0 & -b & 0 \\
0 & 0 & 0 & 0 & a & 0 & a \\
0 & 0 & 0 & a & -b & a & -b
\end{array}\right] .
\end{aligned}
$$

To eliminate the shear locking phenomenon as the thickness of the plate decreases, the MITC3 element based on the first-order shear deformation theory (FSDT) is proposed by Lee and Bathe [1]. In their study, the covariant transverse shear strains of the triangular element are independently interpolated from the covariant transverse shear strains which are evaluated at the middle of triangular element edges, named typing points. The transverse shear strain field associated to typing points with 7 dofs per node can be written as follows:

$$
\gamma^{e}=\mathbf{B}_{s}^{e} \mathbf{d}^{e}
$$

in which

$$
\begin{aligned}
\mathbf{B}_{s}^{e} & =\left[\begin{array}{lll}
\mathbf{B}_{s}^{e(0)} & \mathbf{B}_{s}^{e(1)}
\end{array}\right]^{T}, \\
\mathbf{B}_{s 1}^{e(0)} & =\mathbf{J}^{-1}\left[\begin{array}{llllllll}
0 & 0 & -1 & \frac{a}{3}+\frac{d}{6} & \frac{b}{3}+\frac{c}{6} & 0 & 0 \\
0 & 0 & -1 & \frac{d}{3}+\frac{a}{6} & \frac{c}{3}+\frac{b}{6} & 0 & 0
\end{array}\right], \\
\mathbf{B}_{s 2}^{e(0)} & =\mathbf{J}^{-1}\left[\begin{array}{llllllll}
0 & 0 & -1 & \frac{a}{2}-\frac{d}{6} & \frac{b}{2}-\frac{c}{6} & 0 & 0 \\
0 & 0 & -1 & \frac{d}{6} & \frac{c}{6} & 0 & 0
\end{array}\right], \\
\mathbf{B}_{s 3}^{e(0)} & =\mathbf{J}^{-1}\left[\begin{array}{lllllll}
0 & 0 & 0 & \frac{a}{6} & \frac{b}{6} & 0 & 0 \\
0 & 0 & 1 & \frac{d}{2}-\frac{a}{6} & \frac{c}{2}-\frac{b}{6} & 0 & 0
\end{array}\right], \\
\mathbf{B}_{s 1}^{e(1)} & =c\left[\begin{array}{lllllll}
0 & 0 & 0 & 1 & 0 & 1 & 0 \\
0 & 0 & 0 & 0 & 1 & 0 & 1
\end{array}\right],
\end{aligned}
$$

$$
\begin{aligned}
& \mathbf{B}_{s 2}^{e(1)}=c\left[\begin{array}{lllllll}
0 & 0 & 0 & 1 & 0 & 1 & 0 \\
0 & 0 & 0 & 0 & 1 & 0 & 1
\end{array}\right], \\
& \mathbf{B}_{s 3}^{e(1)}=c\left[\begin{array}{lllllll}
0 & 0 & 0 & 1 & 0 & 1 & 0 \\
0 & 0 & 0 & 0 & 1 & 0 & 1
\end{array}\right],
\end{aligned}
$$

where

$$
\mathbf{J}^{-1}=\frac{1}{2 A_{e}}\left[\begin{array}{cc}
c & -b \\
-d & a
\end{array}\right]
$$

in which $a=x_{2}-x_{1}, b=y_{2}-y_{1}, c=y_{3}-y_{1}$, and $d=x_{3}-$ $x_{1}$ are pointed out in Figure 3 and $A_{e}$ is the area of the threenode triangular element.

Substituting the discrete displacement field into equations (36) and (37), we obtained the discrete system equations for static and free vibration analysis of FG porous plates using MITC3 based on $C^{0}-$ HSDT formulation, respectively, as

$$
\mathbf{K} \mathbf{d}=\mathbf{F},
$$

where $\boldsymbol{K}$ is the stiffness matrix of FG porous plates and $\boldsymbol{F}$ represents the load vector.

$$
\begin{aligned}
\mathbf{K} & =\sum_{e=1}^{n^{e}} \mathbf{K}^{e}, \\
\mathbf{F} & =\sum_{e=1}^{n^{e}} \mathbf{F}^{e},
\end{aligned}
$$

with

$$
\mathbf{K}^{e}=\int_{\Omega_{e}} \mathbf{B}^{\mathrm{T}} \mathbf{D B} \mathrm{d} \Omega_{e}+\int_{\Omega_{e}} \mathbf{B}_{s}^{\mathrm{T}} \mathbf{C} \mathbf{B}_{s} \mathrm{~d} \Omega_{e}
$$

where

$$
\begin{aligned}
\mathbf{B}^{e} & =\left[\begin{array}{lll}
\mathbf{B}_{b}^{e} & \mathbf{B}_{b}^{e(1)} & \mathbf{B}_{b}^{e(2)}
\end{array}\right], \mathbf{B}_{b}^{e}=\left[\begin{array}{ll}
\mathbf{B}_{s}^{e(0)} & \mathbf{B}_{s}^{e(1)}
\end{array}\right], \\
\mathbf{F}^{\mathbf{e}} & =\int_{\Omega_{e}} \mathbf{p N d} \Omega_{e}, \\
\left(\mathbf{K}-\omega^{2} \mathbf{M}\right) \mathbf{d}=0, &
\end{aligned}
$$

where $\omega$ is the natural frequency and $\boldsymbol{M}$ is the mass matrix

$$
\begin{aligned}
\left(\mathbf{K}-\omega^{2} \mathbf{M}\right) \mathbf{d} & =0, \\
\mathbf{M} & =\sum_{e=1}^{n^{e}} \mathbf{M}^{e}, \\
\mathbf{M}^{e} & =\int_{\Omega_{e}} \mathbf{N}^{T} \mathbf{m N d} \Omega_{e} .
\end{aligned}
$$

4.2. Formulation of an ES-MITC3 Method for FG Porous Plates. In the ES-FEM, a domain $\Omega$ is divided into $n^{k}$ smoothing domains $\Omega^{\kappa}$ based on edges of elements, such as $\Omega=\cup_{k=1}^{n^{k}} \Omega^{k}$ and $\Omega_{l}^{\kappa} \cap \Omega_{j}^{\kappa}=\phi$ for $i \neq j$. An edge-based 


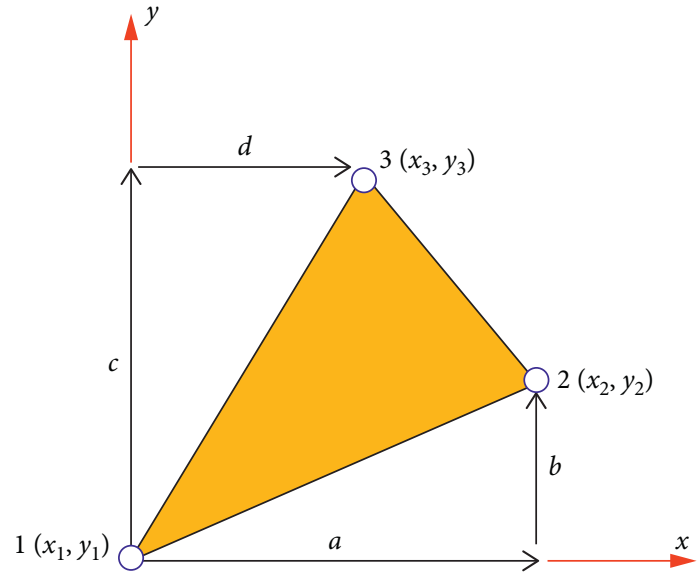

Figure 3: Three-node triangular element in the local coordinates.

smoothing domain $\Omega^{\kappa}$ associated with the inner edge $k$ is formed by connecting two end nodes of the edge to centroids of adjacent MITC3 triangular elements as shown in Figure 4.

Now, applying the edge-based smoothed finite element [2], the smoothed strain $\widetilde{\varepsilon}^{\kappa}$, a smoothed shear strain $\widetilde{\gamma}^{\kappa}$ over the smoothing domain $\Omega^{\kappa}$ can be created by computing the integration of the compatible strain $\varepsilon$ and the shear strain $\gamma$ respectively, in equations (36) and (37) such as

$$
\begin{aligned}
& \widetilde{\varepsilon}^{k}=\int_{\Omega^{k}} \varepsilon \Phi^{k}(\mathrm{X}) \mathrm{d} \Omega, \\
& \tilde{\boldsymbol{\gamma}}^{k}=\int_{\Omega^{k}} \gamma \Phi^{k}(\mathrm{X}) \mathrm{d} \Omega,
\end{aligned}
$$

where $\phi^{k}(\mathbf{x})$ is a given smoothing function that satisfies at least unity property $\int_{\Omega^{k}} \phi^{k}(\mathbf{x}) d \Omega=1$. In this study, we use the constant smoothing function

$$
\Phi^{k}(\mathrm{X})= \begin{cases}\frac{1}{A^{k}}, & \mathrm{X} \in \Omega^{k}, \\ 0, & \mathrm{X} \in \Omega^{k},\end{cases}
$$

in which $A^{k}$ is the area of the smoothing domain $\Omega^{\kappa}$ and is given by

$$
A^{k}=\int_{\Omega^{k}} \mathrm{~d} \Omega=\frac{1}{3} \sum_{i=1}^{n^{e k}} A^{i},
$$

where $n^{e k}$ is the number of the adjacent triangular elements in the smoothing domain $\Omega^{\kappa}$ and $A^{i}$ is the area of the $i$ th triangular element attached to the edge $k$.

By substituting equations (39)-(41) and (51) into equations (69) and (70), the approximation of the smoothed

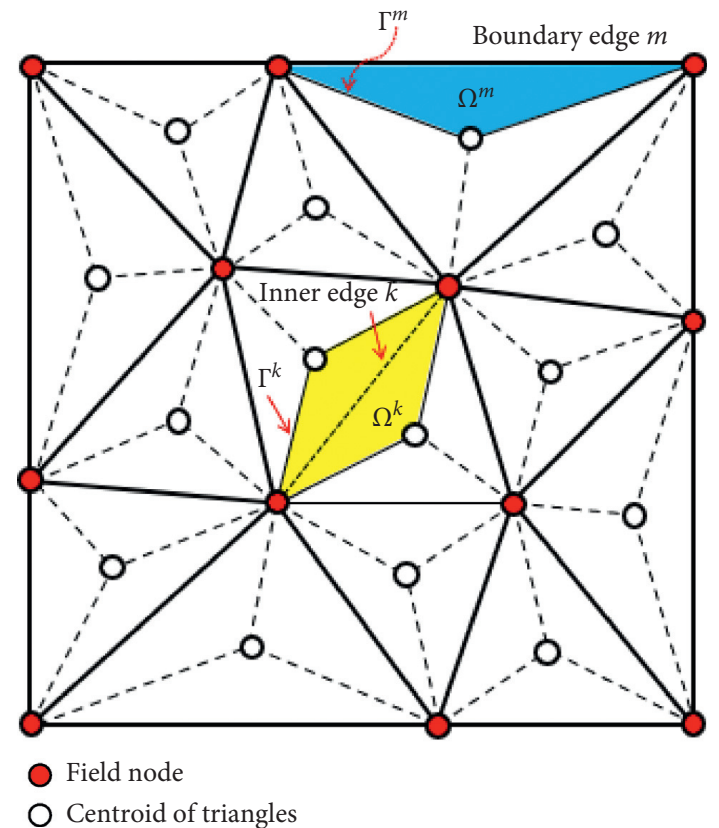

FIgURE 4: The smoothing domain $\Omega^{\kappa}$ formed by triangular elements.

strains on the smoothing domain $V_{G P L}$ can be expressed as follows:

$$
\begin{aligned}
\widetilde{\boldsymbol{\varepsilon}}_{m}^{k} & =\sum_{j=1}^{n^{n k}} \widetilde{\mathbf{B}}_{m j}^{k} \mathbf{d}_{j}^{k}, \\
\widetilde{\mathbf{\kappa}}^{k(1)} & =\sum_{j=1}^{n_{s h}^{n k}} \widetilde{\mathbf{B}}_{b j}^{k(1)} \mathbf{d}_{j}^{k}, \\
\widetilde{\mathbf{\kappa}}^{k(2)} & =\sum_{j=1}^{n_{s h}^{n k}} \widetilde{\mathbf{B}}_{b j}^{k(1)} \mathbf{d}_{j}^{k}, \\
\widetilde{\boldsymbol{\gamma}}^{k(0)} & =\sum_{j=1}^{n_{s h}^{n k}} \widetilde{\mathbf{B}}_{s j}^{k(0)} \mathbf{d}_{j}^{k}, \\
\widetilde{\boldsymbol{\gamma}}^{k(1)} & =\sum_{j=1}^{n_{s h}^{n k}} \widetilde{\mathbf{B}}_{s j}^{k(1)} \mathbf{d}_{j}^{k},
\end{aligned}
$$

where $n_{s h}^{n k}$ is the total number of nodes of the triangular MITC3 elements attached to edge $k$ (i.e., $n_{s h}^{n k}=3$ for boundary edges and $n_{s h}^{n k}=4$ for inner edges as given in Figure 4); $\mathbf{d}_{j}^{k}$ is the nodal dofs associated with the smoothing domain $\Omega^{k} ; \widetilde{\mathbf{B}}_{m j}^{k}, \widetilde{\mathbf{B}}_{b j}^{k(1)}, \widetilde{\mathbf{B}}_{b j}^{k(2)}$ and $\widetilde{\mathbf{B}}_{s j}^{k(0)}$ are the smoothed membrane, the smoothed bending, and the smoothed shear strain gradient matrices, respectively, at the $j$ th node of the elements attached to edge $k$ computed by 


$$
\begin{aligned}
\widetilde{\mathbf{B}}_{m j}^{k} & =\frac{1}{A^{k}} \sum_{i=1}^{n^{e k}} \frac{1}{3} A^{i} \mathbf{B}_{m j}^{e}, \\
\widetilde{\mathbf{B}}_{b j}^{k(1)} & =\frac{1}{A^{k}} \sum_{i=1}^{n^{e k}} \frac{1}{3} A^{i} \mathbf{B}_{b j}^{e(1)}, \\
\widetilde{\mathbf{B}}_{b j}^{k(2)} & =\frac{1}{A^{k}} \sum_{i=1}^{n^{e k}} \frac{1}{3} A^{i} \mathbf{B}_{b j}^{e(2)}, \\
\widetilde{\mathbf{B}}_{s j}^{k(0)} & =\frac{1}{A^{k}} \sum_{i=1}^{n^{e k}} \frac{1}{3} A^{i} \mathbf{B}_{s j}^{e(0)}, \\
\widetilde{\mathbf{B}}_{s j}^{k(1)} & =\frac{1}{A^{k}} \sum_{i=1}^{n^{e k}} \frac{1}{3} A^{i} \mathbf{B}_{s j}^{e(2)} .
\end{aligned}
$$

The global stiffness matrix of FG porous plates using the ES-MITC3 is assembled by

$$
\widetilde{\mathbf{K}}=\sum_{k=1}^{n_{s h}^{k}} \widetilde{\mathbf{K}}^{k}
$$

where $\widetilde{K}^{k}$ is the ES-MITC3 stiffness matrix of the smoothing domain $\Omega^{k}$ and given by

$$
\begin{aligned}
\widetilde{\mathbf{K}}= & \int_{\Omega^{k}}\left(\widetilde{\mathbf{B}}^{k T} \mathbf{D} \widetilde{\mathbf{B}}^{k}+\widetilde{\mathbf{B}}_{s}^{k T} \mathbf{C} \widetilde{\mathbf{B}}_{s}^{k}\right) d \Omega=\widetilde{\mathbf{B}}^{k T} \mathbf{D} \widetilde{\mathbf{B}}^{k} A^{k} \\
& +\widetilde{\mathbf{B}}_{s}^{k T} \mathbf{C} \widetilde{\mathbf{B}}_{s}^{k} A^{k},
\end{aligned}
$$

in which

$$
\widetilde{\mathbf{B}}^{k T}=\left[\widetilde{\mathbf{B}}_{m j}^{k} \widetilde{\mathbf{B}}_{b j}^{k(1)} \widetilde{\mathbf{B}}_{b j}^{k(2)}\right], \widetilde{\mathbf{B}}_{s}^{k T}=\left[\widetilde{\mathbf{B}}_{s j}^{k(0)} \widetilde{\mathbf{B}}_{s j}^{k(1)}\right] .
$$

\section{Numerical Results}

In this section, several numerical examples are verified to illustrate new contributions including (1) verifying the accuracy of the present method for the free vibration and static bending analyses of the FG porous plates reinforced by GPLs by comparing with results in [25] and (2) investigating the influences of the porosity distributions, the GPL dispersion patterns, GPL weight fraction, and the porosity coefficients on the free vibration and static response of the FG porous plates. In the research of Yang et al. [25], it was found that a multilayer plate model has the optimal total layer number $n=12$ which is easy for manufacture and economic efficiency simultaneously. In addition, the error of results between $n=12$ and $n=1000$ is less than $2 \%$. Therefore, $n=12$ is also used in the following examples in this work.

\subsection{Free Vibration Analysis of FG Porous Plates Reinforced by} GPLs. In this section, for convenience in comparing to results in the literature, the nondimensional natural frequency of the plates is given by $\bar{\omega}=\omega a \sqrt{I_{1} / A_{11}}$, in which $I_{1}$ and $A_{11}$ are the values of the inertia moment in mass matrix and the extensional stiffness of FG plate without any pores and GPLs.
5.1.1. The FG Porous Plates with GPL Reinforcement. Firstly, we consider the plate with the length $a=b=2$ and the thickness $h=0.1$ as shown in Figure 5. The material properties of FG porous plates reinforced with GPLs are expressed in Table 1. Tables 2 and 3 show nondimensional frequencies of fully clamped square FG porous plates reinforced by GPLs with varying porosity coefficients and various GPL weight fractions. The results of proposed method are compared with those of several various methods such as MITC3 [33], MITC4 [35], and analytical approach [25]. It can be seen that the ES-MITC3 is a good competitor to quadrilateral shell element MITC4 and gives better accuracy compared with the original triangular elements MITC3. Note that the results of the ES-MITC3 also match well with the analytical solution based on the Chebyshev-Ritz method [25]. It is seen clearly that the increase of porosity coefficient of FG porous plates reinforced with GPLs leads to the reduction of fundamental frequencies. It is because the increase of the porosity coefficient will decrease both the stiffness and mass density of the FG porous plates. In addition, Tables 4 and 5 provide the nondimensional frequencies of FG porous plates with the cases of S-P and $\mathrm{U}-\mathrm{P}$ reinforced by GPL-A and the cases of A-P reinforced by GPL-S, GPL-A, and GPL-U, respectively.

Table 6 shows the nondimensional natural frequencies of the FG porous plates reinforced by GPLs with the different thickness. It can be seen that the FG porous plates have the same thickness; however, the case of A-P reinforced by GPLA gives the minimum natural frequencies. On the contrary, the case of S-P with GPL-S gives the maximum natural frequencies. Moreover, Figure 6 depicts the first six mode shapes of FG porous plate in the case of S-P reinforced by GPL-S $\left(e_{0}=0.2, a / h=20\right.$, and $\left.\Lambda_{\mathrm{GPL}}=1.0 \mathrm{wt}\right)$.

Figure 7 demonstrates the influence of the porosity coefficient and the GPL weight fraction on the natural frequencies of the FG porous square plate. In this case, the FG porous plates are made from S-P reinforced by three different types of GPL patterns. It can be found that the natural frequencies increase gradually when the porosity coefficient reduces and the GPL weight fraction increases. This may be explained by the fact that the presence of the internal pores in the structures with the smaller size and inferior density in the metal matrix leads to the increase of the stiffness of the FG porous plates. In addition, it is clear that the stiffness of the plate structures is significantly improved when a small amount GPLs reinforcement is added in the metal matrix.

\subsubsection{The FG Porous Circular Plates with GPL Reinforcement.} Next, we consider the FG porous circular plate with the fully clamped boundary. The radius of circular plate is $R=1$ and the thickness $h=0.1$ as shown in Figure 8 . The material properties of FG porous reinforced by GPLs are given in Table 1. The domain of circular plate is divided into 318 triangular elements. Table 7 lists the natural frequencies of FG porous circular plate with variable parameters such as the porosity coefficient, the GPL distribution, and the porosity distribution. It can be observed that the FG porous 


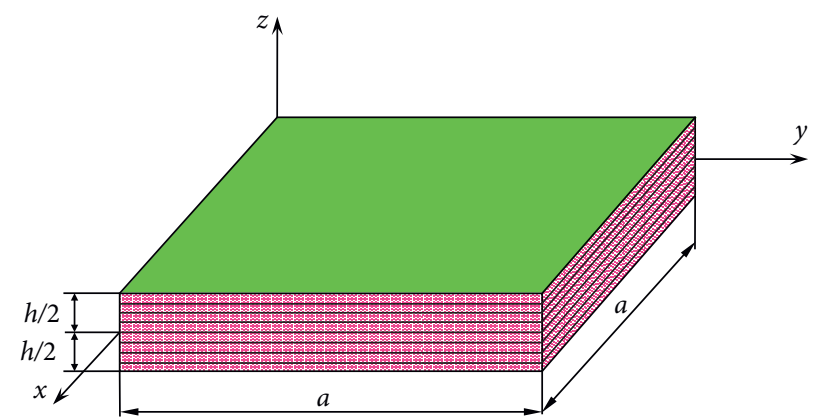

FIgURE 5: The FG porous plates reinforced by GPL model.

TABLE 1: Material properties of FG porous plates reinforced by GPLs.

Material properties Dimensions of GPLs

$E_{m}=130 \mathrm{GPa}$

$v_{m}=0.34$

$\underline{\rho_{m}}=8960 \mathrm{~kg} / \mathrm{m}^{2}$

$E_{G P L}=1.01 \mathrm{TPa}$

$v_{G P L}=0.186$

$\rho_{m}=1062.5 \mathrm{~kg} / \mathrm{m}^{2}$

$t_{G P L}=1.5 \mathrm{~nm}$

TABLE 2: Nondimensional natural frequencies of fully clamped FG porous square plates reinforced by GPLs with $a / h=20$ and $\Lambda_{G P L}=1.0 \%$.

\begin{tabular}{|c|c|c|c|c|c|c|c|c|}
\hline GPLs pattern & $e_{0}$ & Method & 1 & 2 & 3 & 4 & 5 & 6 \\
\hline \multicolumn{9}{|l|}{ S-P } \\
\hline \multirow{17}{*}{ GPL-S } & \multirow{5}{*}{0.2} & Yang & 0.7075 & 1.4057 & 1.4057 & 2.0262 & 2.4337 & 2.4501 \\
\hline & & Present & 0.7073 & 1.4105 & 1.4219 & 2.0576 & 2.4835 & 2.5008 \\
\hline & & MITC3 & 0.7151 & 1.4343 & 1.4517 & 2.1108 & 2.5571 & 2.5761 \\
\hline & & MITC4 & 0.7101 & 1.4310 & 1.4322 & 2.0646 & 2.5430 & 2.5604 \\
\hline & & Yang & 0.7035 & 1.3957 & 1.3958 & 2.0099 & 2.4125 & 2.4290 \\
\hline & \multirow{4}{*}{0.4} & Present & 0.6999 & 1.3915 & 1.4027 & 2.0251 & 2.4405 & 2.4579 \\
\hline & & MITC3 & 0.7078 & 1.4154 & 1.4327 & 2.0791 & 2.5146 & 2.5338 \\
\hline & & MITC4 & 0.7054 & 1.4202 & 1.4215 & 2.0474 & 2.5202 & 2.5376 \\
\hline & & Yang & 0.7017 & 1.3897 & 1.3897 & 1.9985 & 2.3968 & 2.4134 \\
\hline & \multirow{3}{*}{0.6} & Present & 0.6936 & 1.3721 & 1.3830 & 1.9894 & 2.3914 & 2.4090 \\
\hline & & MITC3 & 0.7017 & 1.3966 & 1.4138 & 2.0454 & 2.4672 & 2.0868 \\
\hline & & MITC4 & 0.7037 & 1.4149 & 1.4164 & 2.0376 & 2.5059 & 2.5235 \\
\hline & \multirow{7}{*}{0.4} & Yang & 0.6383 & 1.2729 & 1.2729 & 1.8403 & 2.2147 & 2.2289 \\
\hline & & Present & 0.6424 & 1.2921 & 1.3029 & 1.8979 & 2.3009 & 2.3115 \\
\hline & & MITC3 & 0.6493 & 1.3130 & 1.3289 & 1.9437 & 2.3656 & 2.3817 \\
\hline & & MITC4 & 0.6381 & 1.2887 & 1.2893 & 1.8627 & 2.2980 & 2.3132 \\
\hline & & Yang & 0.6364 & 1.2674 & 1.2674 & 1.8301 & 2.2008 & 2.2152 \\
\hline \multirow{7}{*}{ GPL-U } & & Present & 0.6382 & 1.2807 & 1.2913 & 1.8774 & 2.2732 & 2.2881 \\
\hline & & MITC3 & 0.6451 & 1.3016 & 1.3173 & 1.9234 & 2.3379 & 2.3542 \\
\hline & & MITC4 & 0.6355 & 1.2821 & 1.2829 & 1.8518 & 2.2831 & 2.2989 \\
\hline & \multirow{4}{*}{0.6} & Yang & 0.6379 & 1.2677 & 1.2677 & 1.8276 & 2.1955 & 2.2102 \\
\hline & & Present & 0.6371 & 1.2732 & 1.2836 & 1.8603 & 2.2479 & 2.2632 \\
\hline & & MITC3 & 0.6440 & 1.2943 & 1.3100 & 1.9072 & 2.3132 & 2.3301 \\
\hline & & MITC4 & 0.6372 & 1.2839 & 1.2848 & 1.8521 & 2.2815 & 2.2970 \\
\hline
\end{tabular}

circular plates with U-P and GPL-A have the minimum natural frequency in all cases of investigations. Moreover, Figure 9 illustrates the first six mode shapes of the FG porous plate which is constituted by S-P with the porosity coefficient $\mathrm{e}_{0}=0.2, \quad R / h=10$, and GPLs with weight fraction $\Lambda_{\mathrm{GPL}}=1.0 \mathrm{wt} \%$.

5.2. Static Analysis of FG Porous Plates Reinforced by GPLs. In order to validate the accuracy and stability of the proposed ES-MITC3 based on TSDT for the static analysis problem of the FG porous plate reinforced by GPLs, a fully simply supported FG porous plate subjected to uniform load $q=10^{3} \mathrm{~N} / \mathrm{m}^{2}$ is investigated. The FG porous plate has the thickness-to-width ratio $(h / a)$ of 0.1 , with the porosity coefficient $e_{0}=0.5, \mathrm{~S}-\mathrm{P}$, and GPL-S as shown in Figure 5. Two GPL weight fractions $\Lambda_{\mathrm{GPL}}(1.0 \mathrm{wt} . \%)$ and $(0.5 \mathrm{wt} . \%)$ are studied for five metal matrices given in Table 8. Table 9 presents the percentage of central deflection of the FG porous plate reinforced by GPLs with various metal matrices $\delta w=\left(\left|w_{1}-w_{0}\right| / w_{0}\right) * 100(\%)$, in which $w_{1}$ and $w_{0}$ are the 
TABLE 3: Nondimensional natural frequencies of fully clamped FG porous square plates reinforced by GPLs with $a / h=20$ and $\Lambda_{G P L}=1.0 \%$.

\begin{tabular}{|c|c|c|c|c|c|c|c|c|}
\hline GPLs pattern & $e_{0}$ & Method & 1 & 2 & 3 & 4 & 5 & 6 \\
\hline \multicolumn{9}{|l|}{ U-P } \\
\hline \multirow{17}{*}{ GPL-S } & \multirow{5}{*}{0.2} & Yang & 0.6887 & 1.3696 & 1.3696 & 1.9758 & 2.3744 & 2.3902 \\
\hline & & Present & 0.6892 & 1.3778 & 1.3891 & 2.0138 & 2.4337 & 2.4502 \\
\hline & & MITC3 & 0.6968 & 1.4008 & 1.4178 & 2.0650 & 2.5048 & 2.5230 \\
\hline & & MITC4 & 0.6904 & 1.3926 & 1.3936 & 2.0109 & 2.4785 & 2.4952 \\
\hline & & Yang & 0.6612 & 1.3149 & 1.3149 & 1.8969 & 2.2795 & 2.2947 \\
\hline & \multirow{3}{*}{0.4} & Present & 0.6602 & 1.3203 & 1.3311 & 1.9303 & 2.3332 & 2.3490 \\
\hline & & MITC3 & 0.6674 & 1.3423 & 1.3558 & 1.9794 & 2.4014 & 2.4188 \\
\hline & & MITC4 & 0.6613 & 1.3344 & 1.3354 & 1.9273 & 2.3759 & 2.3919 \\
\hline & \multirow{4}{*}{0.6} & Yang & 0.6285 & 1.2500 & 1.2500 & 1.8032 & 2.1670 & 2.1814 \\
\hline & & Present & 0.6269 & 1.2541 & 1.2644 & 1.8341 & 2.2173 & 2.2323 \\
\hline & & MITC3 & 0.6338 & 1.2751 & 1.2906 & 1.8808 & 2.2822 & 2.2986 \\
\hline & & MITC4 & 0.6279 & 1.2676 & 1.2685 & 1.8313 & 2.2579 & 2.2730 \\
\hline & \multirow{4}{*}{0.2} & Yang & 0.6202 & 1.2383 & 1.2383 & 1.7918 & 2.1574 & 2.1711 \\
\hline & & Present & 0.6242 & 1.2579 & 1.2684 & 1.8505 & 2.2455 & 2.2596 \\
\hline & & MITC3 & 0.6309 & 1.2782 & 1.2936 & 1.8948 & 2.3084 & 2.3238 \\
\hline & & MITC4 & 0.6193 & 1.2521 & 1.2526 & 1.8113 & 2.2362 & 2.2507 \\
\hline & \multirow{4}{*}{0.4} & Yang & 0.5954 & 1.1888 & 1.1888 & 1.7202 & 2.0712 & 2.0844 \\
\hline \multirow{7}{*}{ GPL-U } & & Present & 0.5975 & 1.2044 & 1.2145 & 1.7722 & 2.1508 & 2.1643 \\
\hline & & MITC3 & 0.6039 & 1.2238 & 1.2386 & 1.8148 & 2.2111 & 2.2259 \\
\hline & & MITC4 & 0.5928 & 1.1991 & 1.1996 & 1.7352 & 2.1426 & 2.1564 \\
\hline & \multirow{4}{*}{0.6} & Yang & 0.5660 & 1.1301 & 1.1301 & 1.6353 & 1.9690 & 1.9815 \\
\hline & & Present & 0.5669 & 1.1429 & 1.1525 & 1.6822 & 2.0419 & 2.0546 \\
\hline & & MITC3 & 0.5729 & 1.1614 & 1.1755 & 1.7227 & 2.0992 & 2.1131 \\
\hline & & MITC4 & 0.5625 & 1.1382 & 1.1387 & 1.6475 & 2.0346 & 2.0478 \\
\hline
\end{tabular}

TABLE 4: Nondimensional natural frequencies of fully clamped FG porous square plates reinforced by GPLs with $a / h=20$ and $\Lambda_{G P L}=1.0 \%$.

\begin{tabular}{|c|c|c|c|c|c|c|c|}
\hline GPLs pattern & $e_{0}$ & 1 & 2 & 3 & 4 & 5 & 6 \\
\hline \multicolumn{8}{|l|}{ S-P } \\
\hline & 0.2 & 0.6313 & 1.2697 & 1.2803 & 1.8649 & 2.2608 & 2.2752 \\
\hline \multirow[t]{2}{*}{ GPL-A } & 0.4 & 0.6257 & 1.2556 & 1.2660 & 1.8406 & 2.2287 & 2.2433 \\
\hline & 0.6 & 0.6224 & 1.2440 & 1.2542 & 1.8180 & 2.1969 & 2.2118 \\
\hline \multicolumn{8}{|l|}{ U-P } \\
\hline \multirow{3}{*}{ GPL-A } & 0.2 & 0.6145 & 1.2381 & 1.2485 & 1.8213 & 2.2099 & 2.2238 \\
\hline & 0.4 & 0.5882 & 1.1854 & 1.1953 & 1.7442 & 2.1166 & 2.1298 \\
\hline & 0.6 & 0.5579 & 1.1247 & 1.1341 & 1.6552 & 2.0009 & 2.0215 \\
\hline
\end{tabular}

TABLE 5: Nondimensional natural frequencies of fully clamped FG porous square plates reinforced by GPLs with $a / h=20$ and $\Lambda_{G P L}=1.0 \%$.

\begin{tabular}{|c|c|c|c|c|c|c|c|}
\hline GPLs pattern & $e_{0}$ & 1 & 2 & 3 & 4 & 5 & 6 \\
\hline \multicolumn{8}{|l|}{ A-P } \\
\hline & 0.2 & 0.6911 & 1.3811 & 1.3924 & 2.0181 & 2.4384 & 2.4551 \\
\hline \multirow[t]{3}{*}{ GPL-S } & 0.4 & 0.6606 & 1.3204 & 1.3312 & 1.9297 & 2.3319 & 2.3478 \\
\hline & 0.6 & 0.6179 & 1.2362 & 1.2464 & 1.8081 & 2.1859 & 2.2006 \\
\hline & 0.2 & 0.6126 & 1.2341 & 1.2445 & 1.8153 & 2.2025 & 2.2163 \\
\hline \multirow[t]{3}{*}{ GPL-A } & 0.4 & 0.5814 & 1.1717 & 1.1815 & 1.7240 & 2.0920 & 2.1051 \\
\hline & 0.6 & 0.5403 & 1.0897 & 1.0989 & 1.6044 & 1.9476 & 1.9596 \\
\hline & 0.2 & 0.6265 & 1.2621 & 1.2727 & 1.8563 & 2.2522 & 2.2663 \\
\hline \multirow[t]{2}{*}{ GPL-U } & 0.4 & 0.5998 & 1.2084 & 1.2186 & 1.7775 & 2.1567 & 2.1702 \\
\hline & 0.6 & 0.5637 & 1.1362 & 1.1457 & 1.6719 & 2.0290 & 2.0416 \\
\hline
\end{tabular}

FG porous plate reinforced by GPLs and FG porous plate without GPLs, respectively. From the numerical results, it can be seen that the results of the proposed approach agree well with the IGA method.
Next, we consider the deflection of simply supported FG porous square plate reinforced by GPLs under sinusoidally distributed load $q=q_{0} \sin (\pi x / a) \sin (\pi y / b) \quad$ with $q_{0}=0.1 \mathrm{MPa}$. The plate's length $(a=b=1 \mathrm{~m})$, thickness 
TABLE 6: Nondimensional natural frequencies of the FG porous square plates reinforced by GPLs with various thickness ratios and lengths $\left(a=b=1, \Lambda_{G P L}=1.0 \mathrm{wt} . \%\right.$, and $\left.e_{0}=0.5\right)$.

\begin{tabular}{|c|c|c|c|c|c|c|c|c|c|}
\hline \multirow{2}{*}{$a / h$} & \multicolumn{3}{|c|}{ S-P } & \multicolumn{3}{|c|}{ A-P } & \multicolumn{3}{|c|}{ U-P } \\
\hline & GPL-S & GPL-A & GPL-U & GPL- S & GPL-A & GPL-U & GPL- S & GPL-A & GPL-U \\
\hline \multicolumn{10}{|c|}{ CCCC } \\
\hline 20 & 0.6966 & 0.6237 & 0.6372 & 0.6413 & 0.5625 & 0.5834 & 0.6442 & 0.5736 & 0.5828 \\
\hline 30 & 0.4781 & 0.4246 & 0.4338 & 0.4373 & 0.3810 & 0.3954 & 0.4392 & 0.3887 & 0.3949 \\
\hline 40 & 0.3625 & 0.3209 & 0.3279 & 0.3308 & 0.2875 & 0.2984 & 0.3322 & 0.2933 & 0.2979 \\
\hline 50 & 0.2915 & 0.2577 & 0.2633 & 0.2657 & 0.2306 & 0.2394 & 0.2668 & 0.2353 & 0.2391 \\
\hline \multicolumn{10}{|c|}{ SSSS } \\
\hline 20 & 0.3952 & 0.3499 & 0.3576 & 0.3607 & 0.3134 & 0.3254 & 0.3623 & 0.3198 & 0.3250 \\
\hline 30 & 0.2660 & 0.2349 & 0.2401 & 0.2423 & 0.2101 & 0.2181 & 0.2433 & 0.2144 & 0.2178 \\
\hline 40 & 0.2001 & 0.1766 & 0.1805 & 0.1822 & 0.1579 & 0.1639 & 0.1830 & 0.1611 & 0.1637 \\
\hline 50 & 0.1604 & 0.1415 & 0.1446 & 0.1459 & 0.1264 & 0.1313 & 0.1465 & 0.1290 & 0.1311 \\
\hline
\end{tabular}

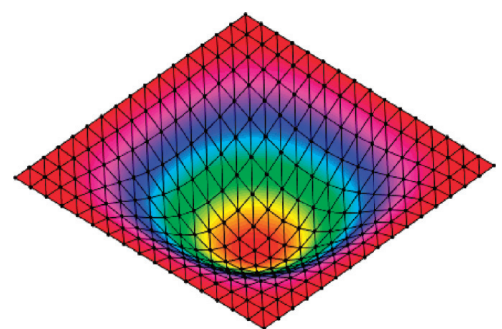

(a)

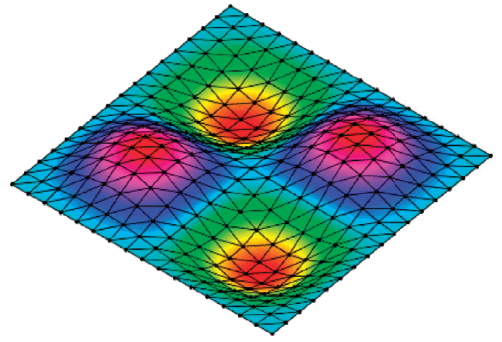

(d)

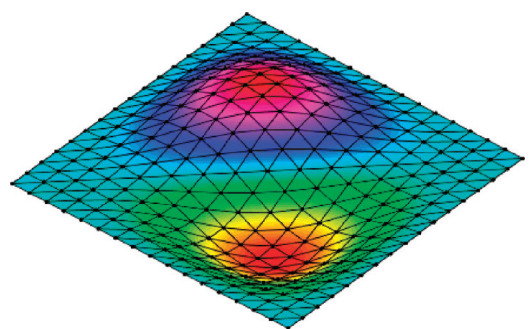

(b)

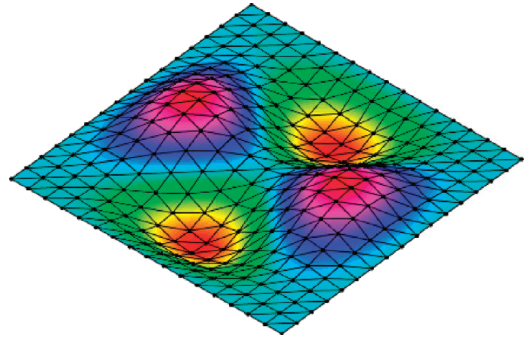

(e)

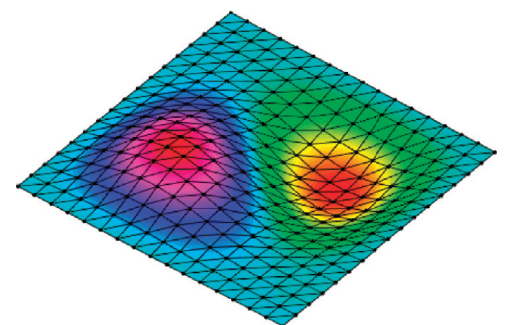

(c)

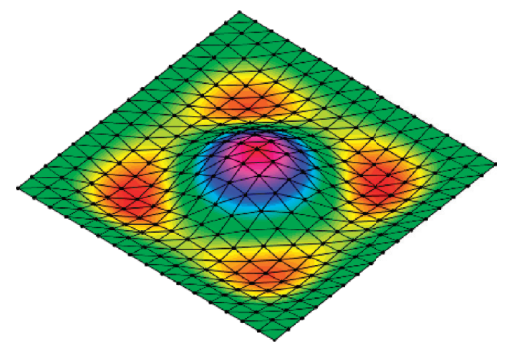

(f)

Figure 6: The first six mode shapes of clamped FG porous plate in the case of S-P reinforced by GPL-S with $\mathrm{e}_{0}=0.2, a / h=20$, and $\Lambda_{\mathrm{GPL}}=1.0 \mathrm{wt}$.\%. (a) Mode 1. (b) Mode 2. (c) Mode 3. (d) Mode 4. (e) Mode 5. (f) Mode 6.

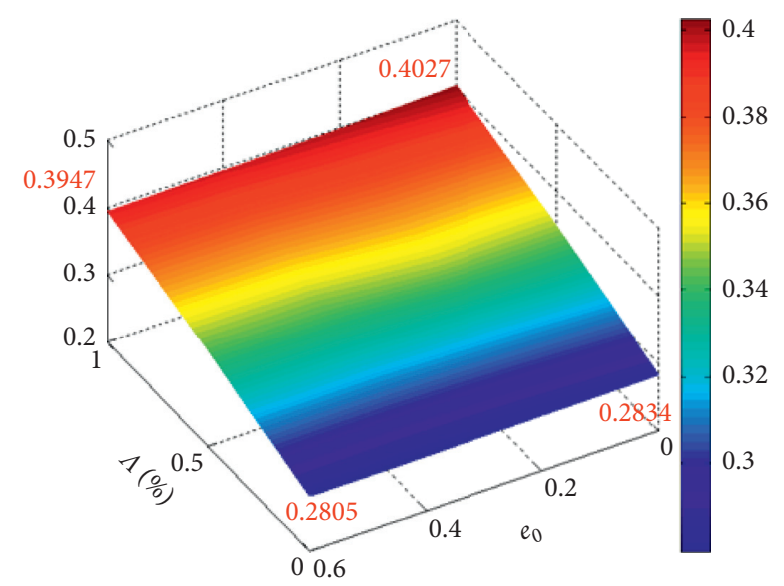

(a)

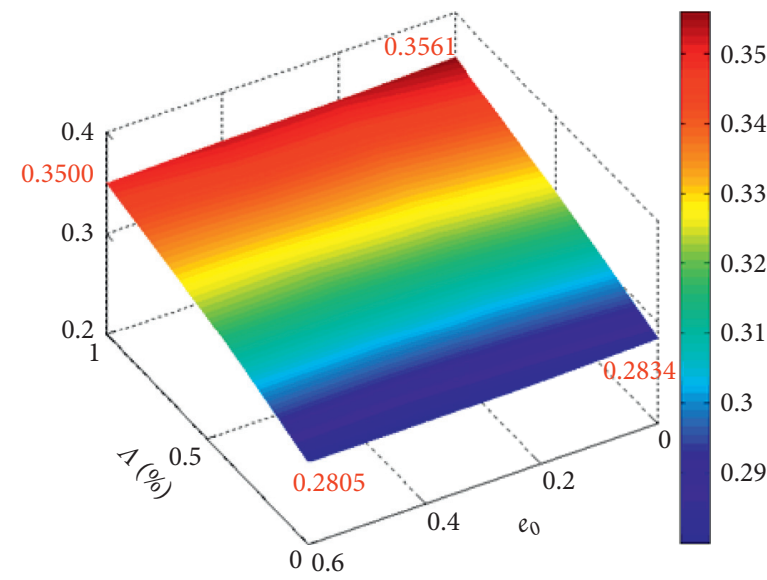

(b)

FIGURE 7: Continued. 


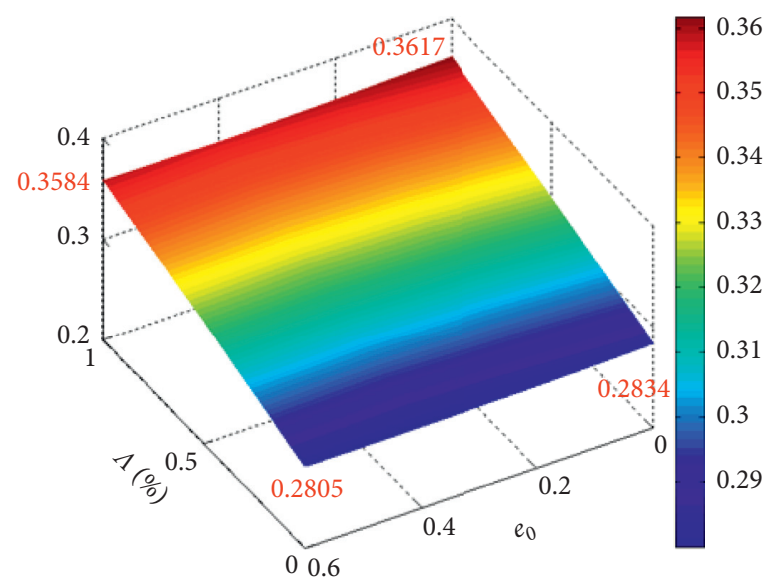

(c)

FIGURE 7: Effect of the porosity coefficient and GPLs on nondimensional natural frequencies of simply supported FG porous square plates with S-P and different GPL dispersion patterns.

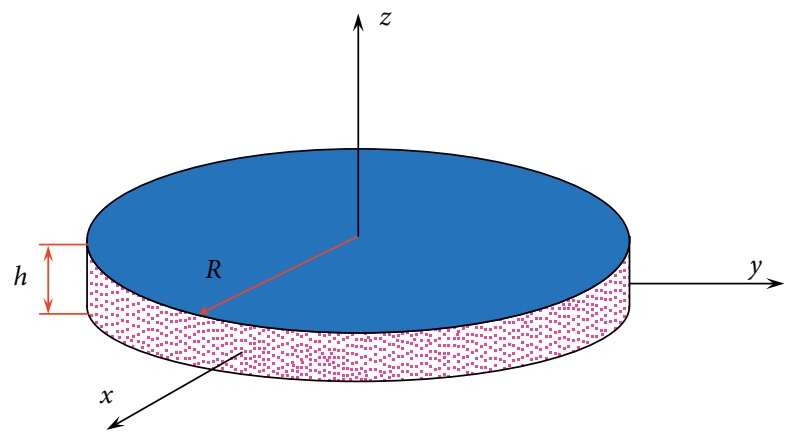

FIGURE 8: The FG porous circular plates reinforced by GPL model.

TABLE 7: Nondimensional natural frequencies of simply supported FG porous circular plates reinforced by GPLs with various thickness ratios $\left(R / h=10\right.$ and $\Lambda_{G P L}=1.0$ wt. $\left.\%\right)$.

\begin{tabular}{|c|c|c|c|c|c|c|c|c|c|}
\hline \multirow{2}{*}{$e_{0}$} & \multicolumn{3}{|c|}{ S-P } & \multicolumn{3}{|c|}{ A-P } & \multicolumn{3}{|c|}{ U-P } \\
\hline & GPL-S & GPL-A & GPL-U & GPL-S & GPL-A & GPL-U & GPL-S & GPL-A & GPL-U \\
\hline 0 & 1.4733 & 1.3502 & 1.3718 & 1.4733 & 1.3502 & 1.3718 & 1.4733 & 1.3502 & 1.3718 \\
\hline 0.1 & 1.4606 & 1.3398 & 1.3622 & 1.4496 & 1.3248 & 1.3497 & 1.4480 & 1.3264 & 1.3476 \\
\hline 0.2 & 1.4473 & 1.3293 & 1.3526 & 1.4237 & 1.2971 & 1.3258 & 1.4213 & 1.3014 & 1.3221 \\
\hline 0.3 & 1.4333 & 1.3187 & 1.3431 & 1.3948 & 1.2668 & 1.2994 & 1.3931 & 1.2749 & 1.2953 \\
\hline 0.4 & 1.4183 & 1.3079 & 1.3336 & 1.3620 & 1.2329 & 1.2698 & 1.3630 & 1.2467 & 1.2667 \\
\hline 0.5 & 1.4019 & 1.2967 & 1.3240 & 1.3240 & 1.1942 & 1.2358 & 1.3308 & 1.2165 & 1.2361 \\
\hline 0.6 & 1.3835 & 1.2848 & 1.3141 & 1.2784 & 1.1491 & 1.1955 & 1.2957 & 1.1836 & 1.2028 \\
\hline
\end{tabular}

( $h=0.05 \mathrm{~m})$, and material properties as well as the dimensions of GPLs are given in Table 1. The number of layers of FG porous plates $n=12$ is applied again in the static analysis. Table 10 shows nondimensional central deflection $(\bar{w}=w / h)$ of the FG porous plates reinforced by GPLs with GPL weight fraction $\Lambda_{\mathrm{GPL}}=1.0 \mathrm{wt}$. $\%$. It can be observed that the FG porous plates with A-P and GPL-A for all cases using the same porosity coefficient give the largest displacement while the S-P and GPL-S give the lowest displacement.

The influences of porosity coefficient and GPL weight fracture on central deflection of the FG porous plates reinforced by three various types of GPLs distribution and the porosity distribution S-P are shown in Figure 10. It can be found that the central displacement of FG porous plate increases gradually when the porosity coefficient increases. As expected, the internal pores existing in the metal matrix of the FG plates with larger size and higher density lead to the reduction of stiffness of plate structure. Besides, we can see that the GPL weight fracture in the metal matrix also has a significant effect on the central deflection of the plates. Accordingly, with the same porosity distribution (S-P) and porosity coefficient, when the GPL weight fracture increases, 


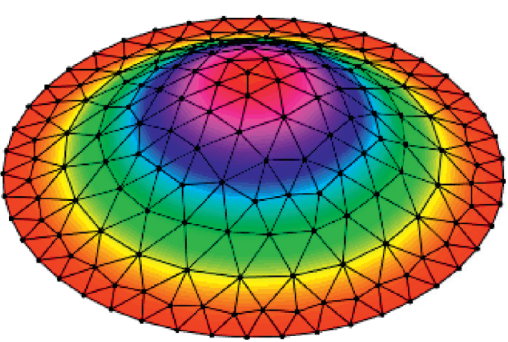

(a)

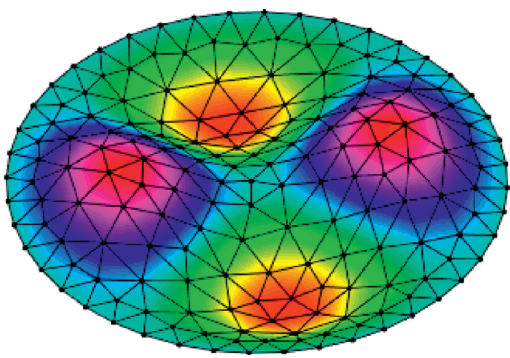

(d)

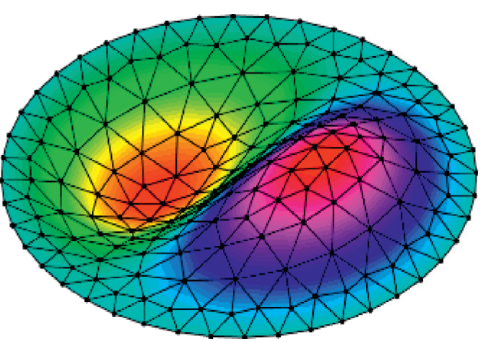

(b)

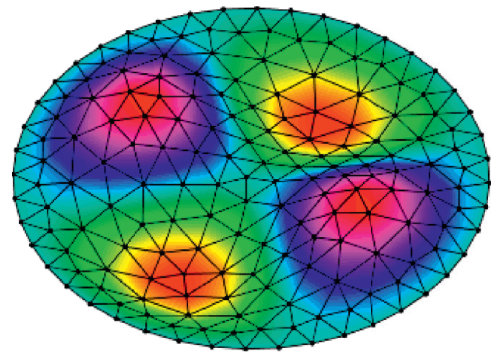

(e)

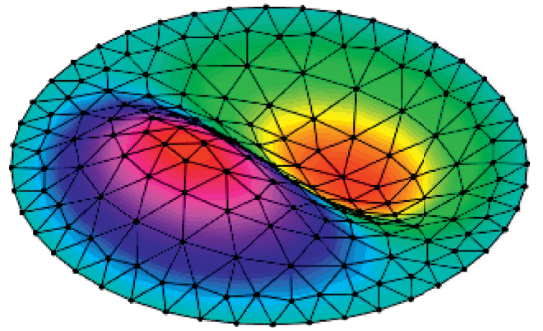

(c)

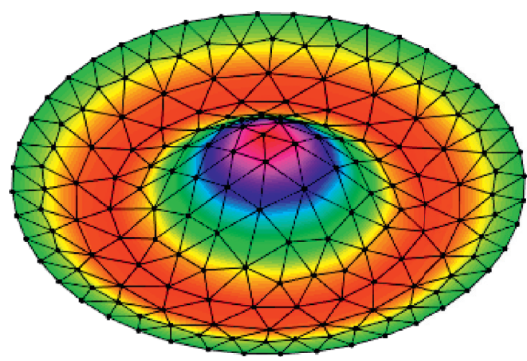

(f)

Figure 9: The first six mode shapes of clamped FG porous circular plate in the case of S-P reinforced by GPL-S with $\mathrm{e}_{0}=0.2, R / h=10$, and $\Lambda_{\mathrm{GPL}}=1.0$ wt.\%. (a) Mode 1. (b) Mode 2. (c) Mode 3. (d) Mode 4. (e) Mode 5. (f) Mode 6.

TABLE 8: Material properties of metal matrix.

\begin{tabular}{lccccc}
\hline & Aluminium & Magnesium & Copper & Nickel & Titanium \\
\hline$E(\mathrm{Gpa})$ & 68.3 & 45 & 130 & 210 & 11645 \\
$\mathrm{~V}$ & 0.34 & 0.35 & 0.34 & 0.31 & 0.33 \\
$\rho\left(\mathrm{kg} / \mathrm{m}^{3}\right)$ & 2689.8 & 1740 & 8960 & 8908 & 4506 \\
\hline
\end{tabular}

TABLe 9: Percentage of central deflection of the FG porous plate with various metal matrices.

\begin{tabular}{|c|c|c|c|c|c|c|}
\hline Method & $\Lambda_{\mathrm{GPL}}$ & Aluminium & Magnesium & Copper & Nickel & Titanium \\
\hline \multicolumn{7}{|l|}{$\delta w$} \\
\hline ES-MITC3 & 10 unt of & 34.851 & 21.551 & 29.877 & 19.354 & 20.137 \\
\hline IGA & 1.0 wt. $\%$ & 35.891 & 22.277 & 31.188 & 19.802 & 20.544 \\
\hline ES-MITC3 & 05 & 21.402 & 35.155 & 44.931 & 31.429 & 32.934 \\
\hline IGA & 0.5 wt. $\%$ & 22.139 & 36.386 & 46.287 & 32.425 & 33.910 \\
\hline
\end{tabular}

TABLE 10: Nondimensional central deflection $\left(10^{3} \bar{w}\right)$ of simply supported FG porous square plates reinforced by GPLs with $a / b=1$, $a / h=20$, and $\Lambda_{\mathrm{GPL}}=1.0 \mathrm{wt} . \%$.

\begin{tabular}{|c|c|c|c|c|c|c|}
\hline \multirow{2}{*}{ GPL pattern } & \multicolumn{6}{|c|}{$e_{0}$} \\
\hline & 0.1 & 0.2 & 0.3 & 0.4 & 0.5 & 0.6 \\
\hline \multicolumn{7}{|l|}{ S-P } \\
\hline GPL-S & 1.8911 & 1.9760 & 2.0695 & 2.1737 & 2.2909 & 2.4250 \\
\hline GPL-A & 2.4183 & 2.5266 & 2.6450 & 2.7753 & 2.9197 & 3.0815 \\
\hline GPL-U & 2.3398 & 2.4401 & 2.5489 & 2.6673 & 2.7971 & 2.9403 \\
\hline \multicolumn{7}{|l|}{ A-P } \\
\hline GPL-S & 1.9349 & 2.0784 & 2.2522 & 2.4689 & 2.7495 & 3.1326 \\
\hline GPL-A & 2.4900 & 2.6931 & 2.9391 & 3.2451 & 3.6391 & 4.1705 \\
\hline GPL-U & 2.3972 & 2.5735 & 2.7850 & 3.0456 & 3.3785 & 3.8247 \\
\hline \multicolumn{7}{|l|}{ U-P } \\
\hline GPL-S & 1.9439 & 2.0944 & 2.2703 & 2.4790 & 2.7317 & 3.0457 \\
\hline GPL-A & 2.4865 & 2.6803 & 2.9072 & 3.1767 & 3.5038 & 3.9112 \\
\hline GPL-U & 2.4096 & 2.5975 & 2.8172 & 3.0782 & 3.3945 & 3.7882 \\
\hline
\end{tabular}




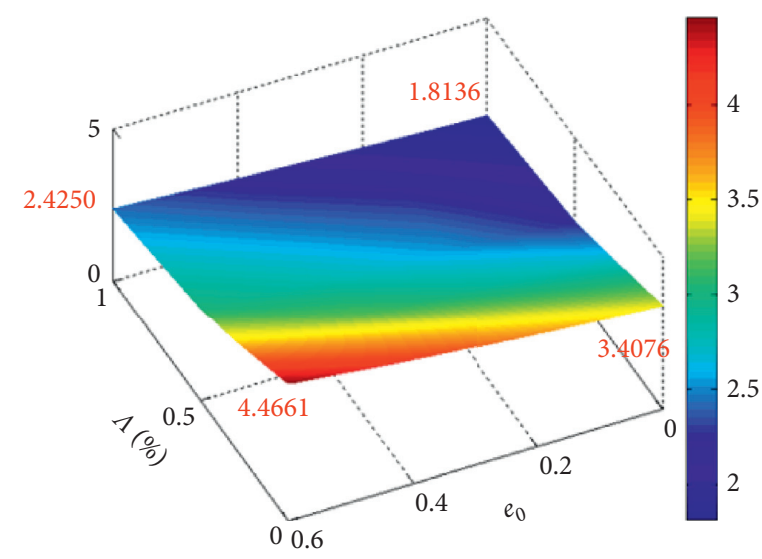

(a)

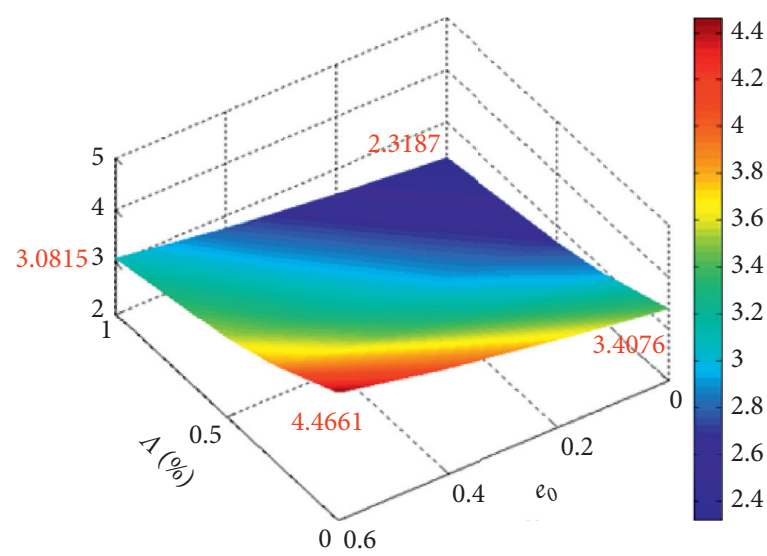

(b)

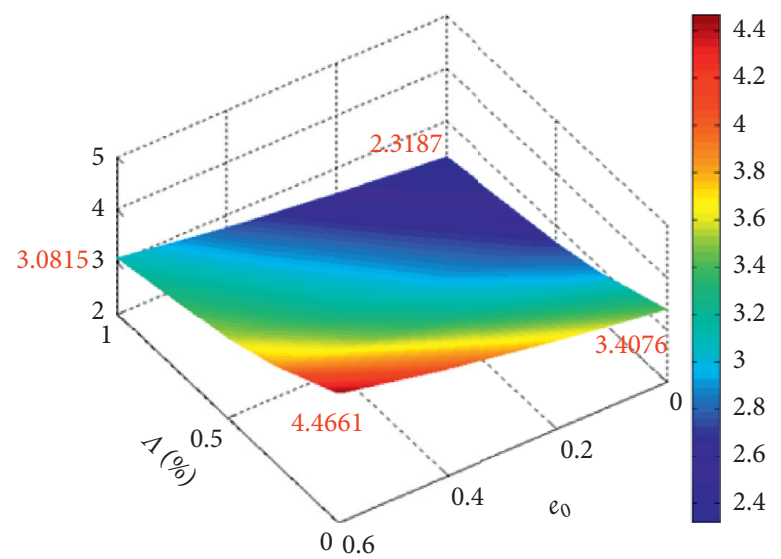

(c)

FIGURE 10: Effect of the porosity coefficient and GPL weight fracture on nondimensional deflection of simply supported FG porous square plates with S-P and different GPL dispersion patterns.

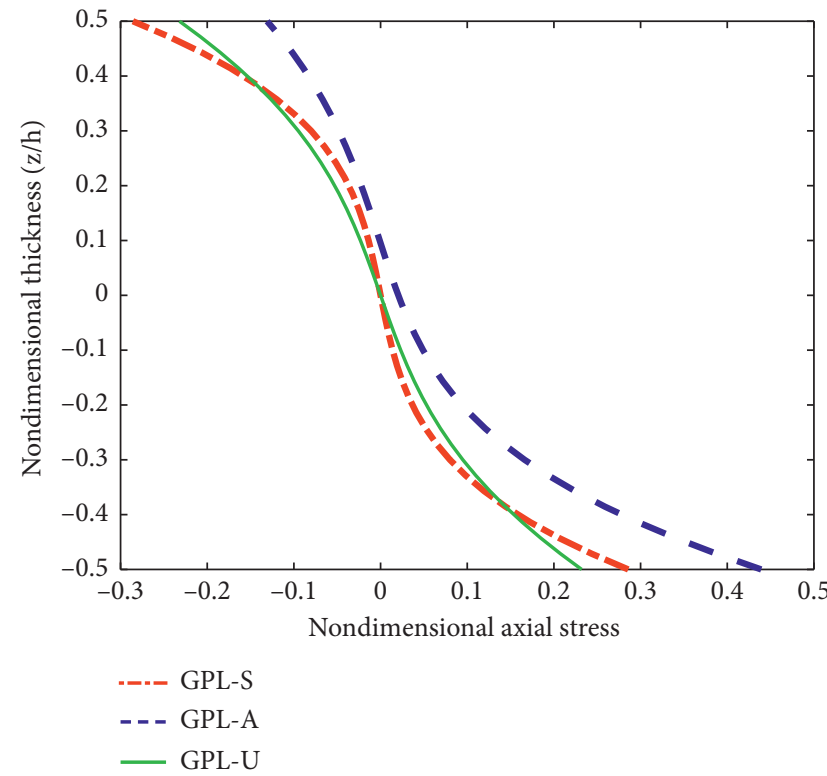

(a)

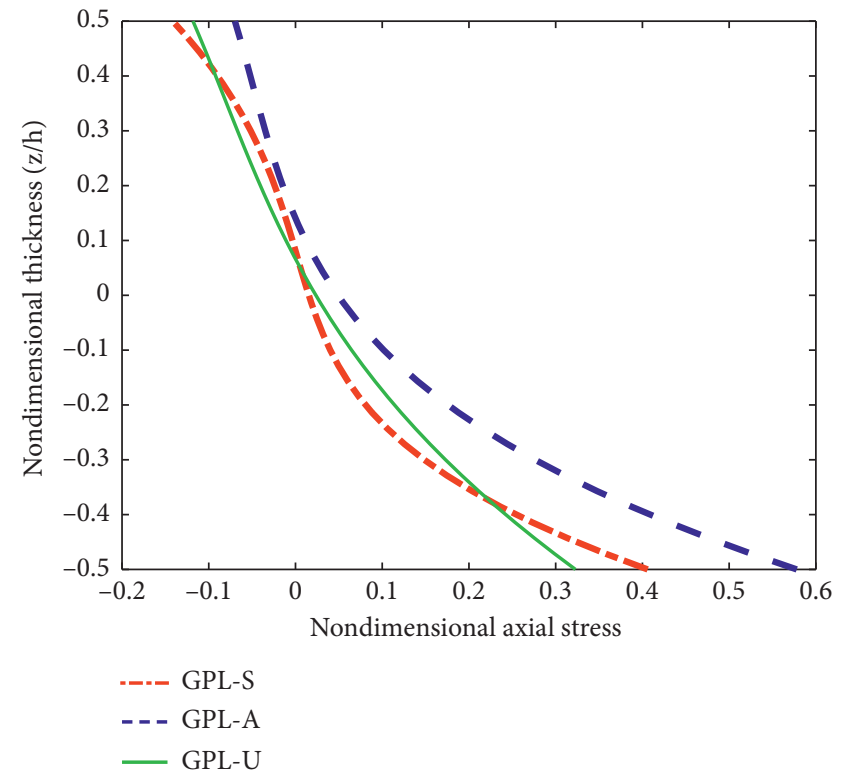

(b)

Figure 11: Continued. 


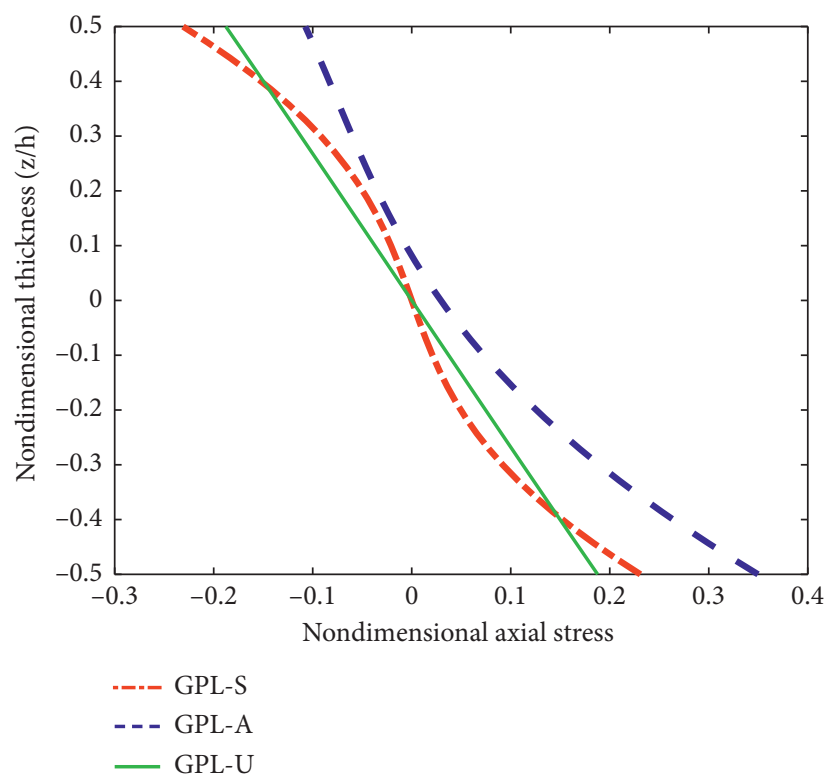

(c)

Figure 11: Nondimensional central axial stress $\sigma_{x x}(a / 2, a / 2, z)$ under three types of porosity distribution and various patterns $\left(e_{0}=0.5\right.$ and $\Lambda_{G P L}=1.0$ wt.\%). (a) S-P. (b) A-P. (c) U-P.

the central displacement will decrease. It can be concluded that the increase of porosity coefficient of the FG porous plates will decrease the density and increase the GPL weight fracture and hence makes the plate become stiffer.

Figure 11 demonstrates the plots of the axial stress $\sigma_{x x}(a / 2, a / 2, z)$ through the thickness of FG porous plates reinforced by GPLs with three types of porosity distribution and various GPL dispersion patterns under sinusoidally distributed load from top surface. It can be seen that the maximum compressive stress at the top surface of FG porous plate is in the case of porosity distribution S-P and GPL-S reinforcement. On the contrary, the maximum tensile stress is in the case of the porosity distribution S-A and GPL-A reinforcement. Note that the FG porous structures reinforced by GPLs are weaker in compression than in tension in most cases of porosity distributions and GPL dispersion patterns.

\section{Conclusions}

In this paper, the static and free vibration analyses of FG porous plates reinforced by GPLs are studied by using the ES-MITC3 based on the HSDT. In this formulation, the strain smoothing technique over the smoothing domains is associated with edges of MITC3 triangular elements to improve the accuracy of the original MITC3 element for structure analysis. From the numerical results, we can draw the following conclusions:

(i) The ES-MITC3 element is simply obtained from linear approximations using 3-node triangular elements, and thus high computational cost is avoided. (ii) The ES-MITC3 uses three-node triangular elements that are much easily generated automatically even for complicated geometry domains.

(iii) The results obtained by ES-MITC3 element are more accurate than those obtained by using the original MITC3 element.

(iv) The proposed method uses the HSDT model which provides more accurate solutions with no demand of the shear correct factors.

(v) The porosity distribution, the porosity coefficient, and the GPL dispersion patterns significantly influence the static and free vibration response of the FG porous plates with GPL reinforcement.

(vi) Numerical results in the present study are useful for calculation, design, and testing of geometrical parameters and material properties in engineering and technologies.

(vii) The present approach can be developed to investigate the FG porous plate reinforced by GPLs subjected to other loads as well as analysis of FG porous shells with GPL reinforcement.

\section{Data Availability}

The data used to support this study are included within the article.

\section{Conflicts of Interest}

The authors declare that they have no conflicts of interest. 


\section{Acknowledgments}

This research was funded by the Vietnam National Foundation for Science and Technology Development (NAFOSTED) under grant no. 107.02-2019.330.

\section{References}

[1] A. S. Rezaei and A. R. Saidi, "Exact solution for free vibration of thick rectangular plates made of porous materials," Composite Structures, vol. 134, pp. 1051-1060, 2015.

[2] P. Leclaire, K. V. Horoshenkov, and A. Cummings, "Transverse vibrations of a thin rectangular porous plate saturated by a fluid," Journal of Sound and Vibration, vol. 247, no. 1, pp. 1-18, 2001.

[3] J. Zhao, F. Xie, A. Wang, C. Shuai, J. Tang, and Q. Wang, "Vibration behavior of the functionally graded porous (FGP) doubly-curved panels and shells of revolution by using a semianalytical method," Composites Part B: Engineering, vol. 157, pp. 219-238, 2019.

[4] S. Coskun, J. Kim, and H. Toutanji, "Bending, free vibration, and buckling analysis of functionally graded porous microplates using a general third-order plate theory," Journal of Composites Science, vol. 3, no. 15, 2019.

[5] D. Dinh, "Nonlinear dynamic response of functionally graded porous plates on elastic foundation subjected to thermal and mechanical loads," Journal of Applied and Computational Mechanics, vol. 4, 2018.

[6] P. Phung-Van, "Isogeometric nonlinear transient analysis of porous FGM plates subjected to hygro-thermo-mechanical loads," Thin-Walled Structures, vol. 10, 2019.

[7] M. R. Barati, "Vibration analysis of porous FG nanoshells with even and uneven porosity distributions using nonlocal strain gradient elasticity," Acta Mechanica, vol. 229, no. 3, pp. 1183-1196, 2018.

[8] M. R. Barati, "A general nonlocal stress-strain gradient theory for forced vibration analysis of heterogeneous porous nanoplates," European Journal of Mechanics-A/Solids, vol. 67, pp. 215-230, 2019.

[9] H. Shahverdi and M. R. Barati, "Vibration analysis of porous functionally graded nanoplates," International Journal of Engineering Science, vol. 120, pp. 82-99, 2017.

[10] M. Forsat, S. Badnava, S. S. Mirjavadi, M. R. Barati, and A. M. S. Hamouda, "Small scale effects on transient vibrations of porous FG cylindrical nanoshells based on nonlocal strain gradient theory," The European Physical Journal Plus, vol. 135, no. 1, p. 81, 2018.

[11] S. S. Mirjavadi, M. Forsat, M. R. Barati et al., "Dynamic response of metal foam FG porous cylindrical micro-shells due to moving loads with strain gradient size-dependency," The European Physical Journal Plus, vol. 134, no. 5, p. 214, 2019.

[12] R. M. Fenjan, L. B. Hamad, and N. M. Faleh, "Mechanicalhygro-thermal vibrations of functionally graded porous plates with nonlocal and strain gradient effects," Advances in Aircraft and Spacecraft Science, vol. 7, no. 2, pp. 169-186, 2020.

[13] F. Ebrahimi, A. Jafari, and M. R. Barati, "Free vibration analysis of smart porous plates subjected to various physical fields considering neutral surface position," Arabian Journal for Science and Engineering, vol. 42, no. 5, pp. 1865-1881, 2017.

[14] M. R. Barati and A. M. Zenkour, "Analysis of postbuckling behavior of general higher-order functionally graded nanoplates with geometrical imperfection considering porosity distributions," Mechanics of Advanced Materials and Structures, vol. 26, no. 12, pp. 1081-1088, 2019.

[15] M. R. Barati and A. M. Zenkour, "Electro-thermoelastic vibration of plates made of porous functionally graded piezoelectric materials under various boundary conditions," Journal of Vibration and Control, vol. 24, no. 10, pp. 19101926, 2018.

[16] M. R. Barati and H. Shahverdi, "Nonlinear vibration of nonlocal four-variable graded plates with porosities implementing homotopy perturbation and Hamiltonian methods," Acta Mechanica, vol. 229, no. 1, pp. 343-362, 2018.

[17] D. Yengejeh, S. Imani, and A. Öchsner, "Carbon nanotubes as reinforcement in composites: a review of the analytical, numerical and experimental approaches," Computational Materials Science, vol. 136, pp. 85-101, 2017.

[18] R. Ansari and J. Torabi, "Semi-analytical postbuckling analysis of polymer nanocomposite cylindrical shells reinforced with functionally graded graphene platelets," Thin-Walled Structures, vol. 144, 2019.

[19] S. S. Mirjavadi, B. M. Afshari, M. R. Barati, and A. M. S. Hamouda, "Nonlinear free and forced vibrations of graphene nanoplatelet reinforced microbeams with geometrical imperfection," Microsystem Technologies, vol. 25, no. 8, pp. 3137-3150, 2019.

[20] M. R. Barati and H. Shahverdi, "Finite element forced vibration analysis of refined shear deformable nanocomposite graphene platelet-reinforced beams," Journal of the Brazilian Society of Mechanical Sciences and Engineering, vol. 42, no. 1, p. 33, 2020.

[21] H. Shahverdi, M. R. Barati, and B. Hakimelahi, "Post-buckling analysis of honeycomb core sandwich panels with geometrical imperfection and graphene reinforced nano-composite face sheets," Materials Research Express, vol. 6, no. 9, 2019.

[22] Z. Li, R. J. Young, N. R. Wilson, I. A. Kinloch, C. Vallés, and $\mathrm{Z}$. Li, "Effect of the orientation of graphene-based nanoplatelets upon the Young's modulus of nanocomposites," Composites Science and Technology, vol. 123, pp. 125-133, 2016.

[23] S. S. Mirjavadi, M. Forsat, A. M. S. Hamouda, and M. R. Barati, "Dynamic response of functionally graded graphene nanoplatelet reinforced shells with porosity distributions under transverse dynamic loads," Materials Research Express, vol. 6, no. 7, 2019.

[24] M. R. Barati and A. M. Zenkour, "Vibration analysis of functionally graded graphene platelet reinforced cylindrical shells with different porosity distributions," Mechanics of Advanced Materials and Structures, vol. 26, no. 18, pp. 1580-1588, 2019.

[25] J. Yang, D. Chen, and S. Kitipornchai, "Buckling and free vibration analyses of functionally graded graphene reinforced porous nanocomposite plates based on Chebyshev-Ritz method," Composite Structures, vol. 193, pp. 281-294, 2018.

[26] K. Gao, W. Gao, D. Chen, and J. Yang, "Nonlinear free vibration of functionally graded graphene platelets reinforced porous nanocomposite plates resting on elastic foundation," Composite Structures, vol. 204, pp. 831-846, 2018.

[27] T. J. Hughes, J. A. Cottrell, and Y. Bazilevs, "Isogeometric analysis: CAD, finite elements, NURBS, exact geometry and mesh refinement," Computer Methods in Applied Mechanics and Engineering, vol. 194, no. 39-41, pp. 4135-4195, 2005.

[28] Y. Wang, Z. Liao, M. Ye, Y. Zhang, W. Li, and Z. Xia, "An efficient isogeometric topology optimization using multilevel mesh, MGCG and local-update strategy," Advances in Engineering Software, vol. 139, p. 102733, 2020. 
[29] Y. Wang, H. Xu, and D. Pasini, "Multiscale isogeometric topology optimization for lattice materials," Computer Methods in Applied Mechanics and Engineering, vol. 316, pp. 568-585, 2017.

[30] S. Shi, "Data-driven structural design optimization for petalshaped auxetics using isogeometric analysis," Computer Modeling in Engineering \& Sciences, vol. 122, no. 2, pp. 433-458, 2020.

[31] K. Li, D. Wu, X. Chen et al., "Isogeometric analysis of functionally graded porous plates reinforced by graphene platelets," Composite Structures, vol. 204, pp. 114-130, 2018.

[32] N. V. Nguyen, J. Lee, and H. Nguyen-Xuan, "Active vibration control of GPLs-reinforced FG metal foam plates with piezoelectric sensor and actuator layers," Composites Part B: Engineering, vol. 172, pp. 769-784, 2019.

[33] A. Wang, H. Chen, Y. Hao, and W. Zhang, "Vibration and bending behavior of functionally graded nanocomposite doubly-curved shallow shells reinforced by graphene nanoplatelets," Results in Physics, vol. 9, pp. 550-559, 2018.

[34] N. V. Nguyen, H. Nguyen-Xuan, D. Lee, and J. Lee, "A novel computational approach to functionally graded porous plates with graphene platelets reinforcement," Thin-Walled Structures, vol. 150, p. 106684, 2020.

[35] P.-S. Lee and K.-J. Bathe, "Development of MITC isotropic triangular shell finite elements," Computers \& Structures, vol. 82, no. 11-12, pp. 945-962, 2004.

[36] G. R. Liu, T. Nguyen-Thoi, and K. Y. Lam, “An edge-based smoothed finite element method (ES-FEM) for static, free and forced vibration analyses of solids," Journal of Sound and Vibration, vol. 320, no. 4-5, pp. 1100-1130, 2009.

[37] H. Nguyen-Xuan, G. R. Liu, T. Nguyen-Thoi, and C. NguyenTran, "An edge-based smoothed finite element method (ESFEM) for analysis of two-dimensional piezoelectric structures," Smart Materials and Structures, vol. 18, 2009.

[38] T. Nguyen-Thoi, G. R. Liu, H. C. Vu-Do, and H. NguyenXuan, "An edge-based smoothed finite element method for visco-elastoplastic analyses of $2 \mathrm{D}$ solids using triangular mesh," Computational Mechanics, vol. 45, no. 1, pp. 23-44, 2009.

[39] G. R. Liu, H. Nguyen-Xuan, and T. Nguyen-Thoi, “An edgebased smoothed finite element method for primal-dual shakedown analysis of structures," International Journal for Numerical Methods in Engineering, vol. 82, no. 7, pp. 917-938, 2010.

[40] T. Nguyen-Thoi, G. R. Liu, and H. Nguyen-Xuan, "An n-sided polygonal edge-based smoothed finite element method (nESFEM) for solid mechanics," International Journal for $\mathrm{Nu}$ merical Methods in Biomedical Engineering, vol. 27, no. 9, pp. 1446-1472, 2010.

[41] G. R. Liu and T. T. Nguyen, Smoothed Finite Element Methods, CRC Press, Taylor and Francis Group, NewYork, NY, USA, 2010.

[42] T. Chau-Dinh, Q. Nguyen-Duy, and H. Nguyen-Xuan, "Improvement on MITC3 plate finite element using edgebased strain smoothing enhancement for plate analysis," Acta Mechanica, vol. 228, no. 6, pp. 2141-2163, 2017.

[43] T.-K. Nguyen, V.-H. Nguyen, T. Chau-Dinh, T. P. Vo, and H. Nguyen-Xuan, "Static and vibration analysis of isotropic and functionally graded sandwich plates using an edge-based MITC3 finite elements," Composites Part B: Engineering, vol. 107, pp. 162-173, 2016.

[44] Q.-H. Pham, T.-V. Tran, T.-D. Pham, and D.-H. Phan, “An edge-based smoothed MITC3 (ES-MITC3) shell finite element in laminated composite shell structures analysis," International Journal of Computational Methods, vol. 34, 2017.

[45] Q.-H. Pham, T.-D. Pham, V. T. Quoc, and D.-H. Phan, "Geometrically nonlinear analysis of functionally graded shells using an edge-based smoothed MITC3 (ES-MITC3) finite elements," Engineering with Computers, vol. 36, no. 3, pp. 1069-1082, 2020.

[46] D. Pham-Tien, H. Pham-Quoc, T. Vu-Khac, and N. NguyenVan, "Transient analysis of laminated composite shells using an edge-based smoothed finite element method," 2017.

[47] K.-U. Bletzinger, M. Bischoff, and E. Ramm, "A unified approach for shear-locking-free triangular and rectangular shell finite elements," Computers \& Structures, vol. 75, 2000.

[48] T. Nguyen-Thoi, P. Phung-Van, H. Nguyen-Xuan, and C. Thai-Hoang, "A cell-based smoothed discrete shear gap method using triangular elements for static and free vibration analyses of Reissner-Mindlin plates," International Journal for Numerical Methods in Engineering, vol. 91, no. 7, pp. 705-741, 2012.

[49] K.-J. Bathe and E. N. Dvorkin, "A formulation of general shell elements - the use of mixed interpolation of tensorial components," International Journal for Numerical Methods in Engineering, vol. 22, 1986.

[50] A. P. Roberts and E. J. Garboczi, "Elastic moduli of model random three-dimensional closed-cell cellular solids," Acta Materialia, vol. 49, no. 2, pp. 189-197, 2001.

[51] A. P. Roberts and E. J. Garboczi, "Computation of the linear elastic properties of random porous materials with a wide variety of microstructure," Proceedings of the Royal Society of London. Series A: Mathematical, Physical and Engineering Sciences, vol. 458, pp. 1033-1054, 2002.

[52] M. A. Rafiee, J. Rafiee, Z. Wang, H. Song, Z.-Z. Yu, and N. Koratkar, "Enhanced mechanical properties of nanocomposites at low graphene content," ACS Nano, vol. 3, no. 12, pp. 3884-3890, 2009.

[53] C. A. Shankara and N. G. R. Iyengar, "A C0Element for the free vibration analysis of laminated composite plates," Journal of Sound and Vibration, vol. 191, no. 5, pp. 721-738, 1996. 